This item was submitted to Loughborough's Research Repository by the author.

Items in Figshare are protected by copyright, with all rights reserved, unless otherwise indicated.

\title{
Experimental and numerical study of full-scale scissor type bridge
}

PLEASE CITE THE PUBLISHED VERSION

http://dx.doi.org/10.1016/j.autcon.2016.05.007

\section{PUBLISHER}

(c) Elsevier

\section{VERSION}

AM (Accepted Manuscript)

\section{PUBLISHER STATEMENT}

This work is made available according to the conditions of the Creative Commons Attribution-NonCommercialNoDerivatives 4.0 International (CC BY-NC-ND 4.0) licence. Full details of this licence are available at: https://creativecommons.org/licenses/by-nc-nd/4.0/

\section{LICENCE}

CC BY-NC-ND 4.0

\section{REPOSITORY RECORD}

Chikahiro, Yuki, Ichiro Ario, Masatoshi Nakazawa, Syuichi Ono, Jan Holnicki-Szulc, Piotr Pawlowski, Cezary Graczykowski, and Andrew Watson. 2016. "Experimental and Numerical Study of Full-scale Scissor Type Bridge". figshare. https://hdl.handle.net/2134/21825. 


\title{
Experimental and Numerical Study of Full-Scale Scissor Type Bridge
}

\author{
Yuki Chikahiro $^{\mathrm{a}}$, Ichiro Ario*b, Masatoshi Nakazawa ${ }^{\mathrm{c}}$, Syuichi Ono ${ }^{\mathrm{d}}$, \\ Jan Holnicki-Szulc ${ }^{\mathrm{e}}$, Piotr Pawlowski ${ }^{\mathrm{e}}$, Cezary Graczykowski ${ }^{\mathrm{e}}$, \\ Andrew Watson ${ }^{\mathrm{f}}$ \\ ${ }^{a}$ Department of Water Environment and Civil Engineering, Shinsyu University, Japan \\ ${ }^{b}$ Department of Civil \& Environmental Engineering, Hiroshima University, Japan \\ ${ }^{c}$ Department of Civil and Environmental Engineering, Tohoku Gakuin University, Japan \\ ${ }^{d}$ Japan Construction Method and Machinery Research Institute, Japan \\ ${ }^{e}$ Institute of Fundamental Technological Research, Polish Academy of Sciences, Poland \\ ${ }^{f}$ Department of Aeronautical and Automotive Engineering, Loughborough University, U.K.
}

\begin{abstract}
Mobile Bridge $^{\mathrm{TM}}$ is a deployable bridge that uses a scissors mechanism to achieve its useful structural form. The bridge has a compact size in its undeployed state and can be transported easily to where it is needed. Its rapid deployment makes this type of bridge very useful in areas struck by natural disasters by enabling vehicles to cross terrain that has been made impassable. In previous research, experiments and analyses were conducted on a small scale bridge designed for pedestrians. In order to consider a bridge of increased size it is necessary to assess whether design and analysis techniques of the small scale bridge are applicable to the full scale one. In this paper, we consider a full-scale deployable bridge with a lower deck and two scissor units, that allows for a light vehicle to pass across. We have carried out a light vehicle loading test in order to investigate its basic structural characteristics. Furthermore, the paper presents the theoretical design method and numerical models based on the experimental work followed by validation and comparison with the obtained experimental values.
\end{abstract}

Keywords: Full-scale Mobile Bridge, Scissor type of emergency bridge,

\footnotetext{
* Corresponding author

Email address: mario@hiroshima-u.ac.jp (Ichiro Ario*)
} 
Scissors mechanism, Vehicle loading test

\section{Introduction}

The scissors mechanism in its most basic form consists of two linear elements joined at their centres by a pivot providing a hinge-connection. In the fully deployed state the two members are in the shape of the character ' $\mathrm{X}$ ' creating the deployed single scissor unit. This basic scissor unit is connected to the next unit by two hinges as shown in Fig. 1. The structure is deployable and has a large ratio of length from the fully extended state to the folded state. In the nondeployed or compact state the structure can be easily transported or stored for future reuse. Hence this mechanism is particularly useful for structural systems that need to be transported and stored in a very limited space.

This concept of a scissor type mechanism was suggested by E. P. Pinero, an architect from Spain. He applied this idea to a deployable roof structure and obtained a patent in 1961 [1]. After this successful application, T. R. Zeigler and F. Escring focused on the geometric layout design of the scissor units and put forward deployable domes using the mechanism [2], [3]. Recently M. Saito [4] has analyzed the strength and stability of scissor structures reinforced with a string system. Indeed, scissor type structures are increasingly used in a wide range of mechanical and space engineering fields [5], 6]. However in the field of civil engineering, there is a few published literature, including patents, exploring the application of a scissor mechanism to bridges [7], 8].

Now, existing bridges with rapid deployable systems are mainly classified fol-

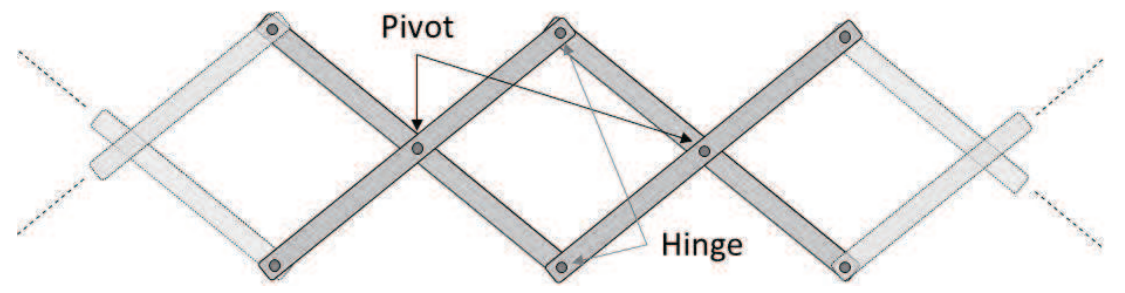

Figure 1: Basic concept of a scissor structure. 
lowing four categories [9]: (1) rapidly erectable gap-crossing bridges, (2) vehiclelaunched bridges, (3) river-crossing solutions, and (4) causeways. Major temporary bridge used in emergency situations, such as the Bailey and Medium Girder Bridge, are classified in (1); they are prefabricated truss-block type bridges which require, to some degree, construction yards and heavy machinery on site. Even some erectable bridges are possible to build it up manually, it requires a number of trained human resources, sometimes over hundred [10].

The authors focused on the advantage of scissors mechanism, and have put forward a new concept of a foldable emergency bridge called Mobile Bridge (herein called MB) [1]], [12], based on the previous study of the optimization and control of folding structures [13], 14]. These papers show an optimum shaped frame in the beam structure. The MB is an assembly of this presented frame which utilises the scissor mechanism. Successful application of the scissors mechanism to the bridge structure should result in a structure with the following attributes:

- reduced transport time compared to a more typical temporary bridge,

- ease of deployment and folding with only one control force,

- efficiency of size comparing between the deployed and folded state.

40 Moreover, in order to decrease complexity of the structure the number of individual components as well as the level of manual operations required for full deployment should be minimised. This reduces the time required for deployment and folding of the structure and the need for specialist to operate the bridge. These advantages, if realized, can remove practical problems related to construction of temporary bridges on site that typically require heavy machinery and a wide construction area. Thus, the MB enables a simpler and more rapid construction compared with the aforementioned temporary bridges.

The MB has a reduced live load capacity and span compared with Bailey type and other bridges because of the absence of upper and lower chord members that, 50 when present, resist bending moment. The resulting lighter bridge can therefore 


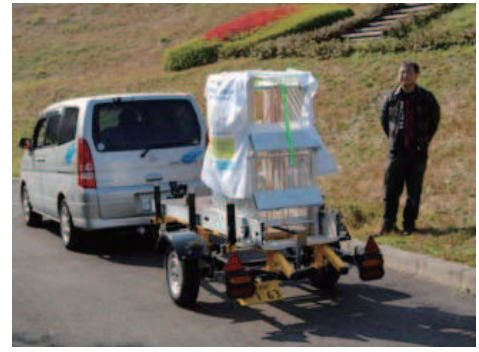

(a)

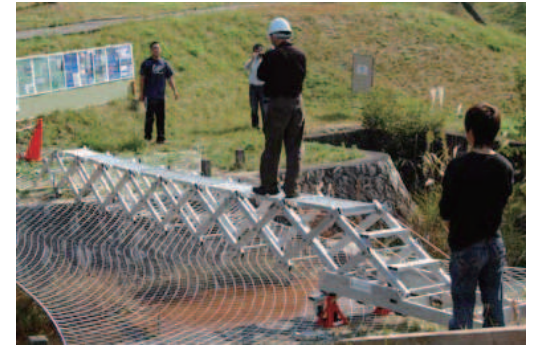

(b)

Figure 2: Pedestrian type of MB using scissors mechanism in its structural form. (a) Store condition. (b) In service state.

be assembled more quickly and whose component parts can be transported in a light vehicle. Smaller scale temporary bridges like MB have the higher potential to be of significant benefit in disaster areas even if the live load capacity is lower than other larger temporary bridges.

In order to construct a design methodology, previous experiments and analyses were conducted using a small scale of pedestrian type of MB [15], which is shown in Fig. 2. This pedestrian bridge is defined as an upper deck bridge since the flat surfaces walked on by pedestrians are aligned at the line of top hinges. That research examined the basic mechanical and structural characteristics of the MB under two sets of boundary conditions. During the deployment phase, the bridge is supported only at one end resulting in cantilever boundary conditions. Once deployed the bridge has two supports hence the deployed, second, condition is the simply supported beam case, where the supports have horizontal and vertical displacement constraint.

In the case of the larger vehicular-scale scissor type bridge, it is necessary to consider the impact of the size of the structure on the design methodology and assess whether the previous results obtained for a pedestrian structure can be applicable. Hence in this paper, we introduce a vehicle scaled MB (herein called MB1.0) composed of two scissor units. The paper presents analytical and numerical models for a simplified design of MB1.0 validated by experimental results. The experimental testing with vehicle loading provides the stress dis- 
tribution and stress changes as the vehicle travels over the bridge, which allows for evaluation of mechanical characteristic and safety factors for the bridge.

\section{Modelling of a scissor structure based on equilibrium equations}

In this section, a basic modelling method with the traversing load for a scissor structure is introduced based on the author's previous work [16].

\subsection{Basic theoretical concepts for the scissor structure}

A two scissor units structure model with the nodal forces acting only on hinge, pivot and pin supports at both-ends is shown in Fig. 3, All members have the same length and the same angle of inclination $\theta$, measured from the vertical direction. The length and height of a scissor unit are defined as $\lambda$ and 2h. Fig. 3(b) shows the two separates scissor unit. The left hand scissor unit consists of nodes $A, C_{L}, D, F, G_{L}$ and the second scissor unit consists of nodes $\mathrm{C}_{\mathrm{R}}, \mathrm{B}, \mathrm{E}, \mathrm{G}_{\mathrm{R}}, \mathrm{H}$. All nodal points are considered as hinge. All loading are applied at nodal locations only hence no bending moments are transmitted or applied at these nodal junctions.

The horizontal $(\mathrm{H})$ and vertical $(\mathrm{V})$ equilibrium equations for the left hand side unit are given as the following

$$
\begin{aligned}
\Sigma H:\left(H_{A}+H_{C L}\right)+\left(H_{F}+H_{G L}\right)+H_{D} & =0 \\
\Sigma V:\left(V_{A}+V_{C L}\right)+\left(V_{F}+V_{G L}\right)+V_{D} & =0
\end{aligned}
$$

Moment equilibrium for the joints $\mathrm{A}, \mathrm{C}_{\mathrm{L}}, \mathrm{F}$ and $\mathrm{G}_{\mathrm{L}}$ are expressed as

$$
\begin{aligned}
& \Sigma M_{\mathrm{A}}: 2 h\left(H_{F}+H_{G L}\right)-\lambda\left(V_{C L}+V_{G L}\right)-\frac{\lambda}{2} V_{D}+h H_{D}=0 \\
& \Sigma M_{\mathrm{CL}}: 2 h\left(H_{F}+H_{G L}\right)+\lambda\left(V_{A}+V_{F}\right)+\frac{\lambda}{2} V_{D}+h H_{D}=0 \\
& \Sigma M_{\mathrm{F}}:-2 h\left(H_{A}+H_{C L}\right)-\lambda\left(V_{C L}+V_{G L}\right)-\frac{\lambda}{2} V_{D}-h H_{D}=0 \\
& \Sigma M_{\mathrm{GL}}:-2 h\left(H_{A}+H_{C L}\right)+\lambda\left(V_{A}+V_{F}\right)+\frac{\lambda}{2} V_{D}-h H_{D}=0
\end{aligned}
$$




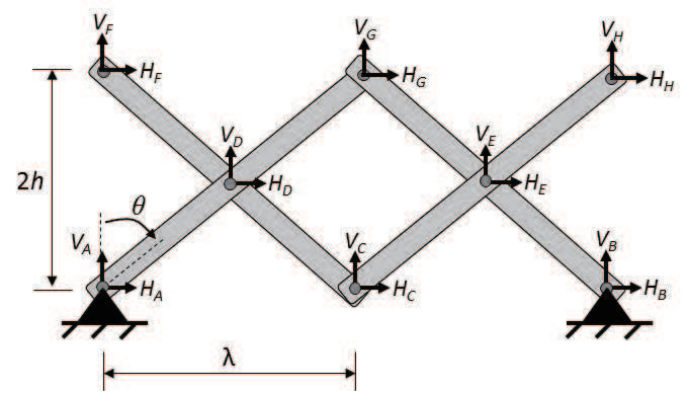

(a)

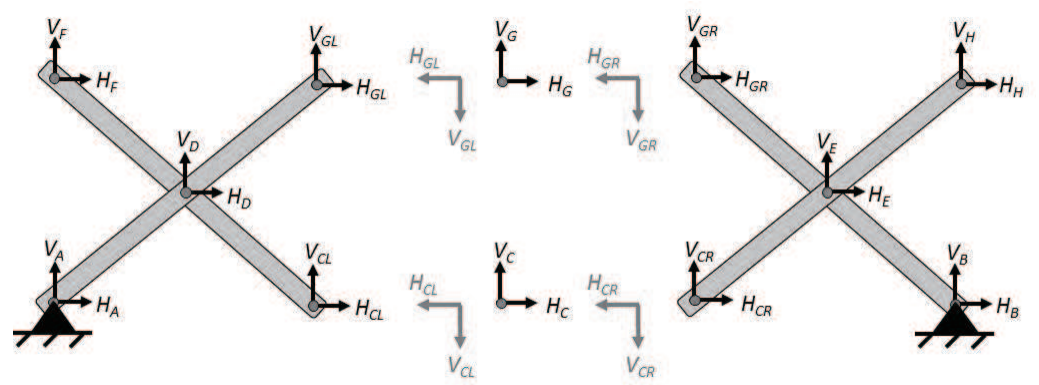

(b)

Figure 3: Theoretical model of the two scissor units structure. (a) Two scissor units structure model with pin supports at both-ends. (b) Equilibrium of the two separate scissor unit at hinge points $\mathrm{C}$ and $\mathrm{G}$.

90 The moment equilibrium equations Eq.(3) - Eq.(6) can be linearly combined as shown to produce the following equations

$$
\begin{aligned}
& \text { (44) - (6) }: \quad \zeta\left(H_{A}+H_{C L}\right)+\zeta\left(H_{F}+H_{G L}\right)+\zeta H_{D}=0 \rightarrow \text { Eq.(1) } \\
& \text { (44) - (3) : } \lambda\left(V_{C L}+V_{G L}\right)+\lambda\left(V_{A}+V_{F}\right)+\lambda V_{D}=0 \rightarrow \text { Eq.(2) } \\
& \text { (3) - (5) }: \zeta\left(H_{A}+H_{C L}\right)+\zeta\left(H_{F}+H_{G L}\right)+\zeta H_{D}=0 \rightarrow \text { Eq.(1) } \\
& \text { (66) - (5) : } \lambda\left(V_{C L}+V_{G L}\right)+\lambda\left(V_{A}+V_{F}\right)+\lambda V_{D}=0 \rightarrow \text { Eq.(2) }
\end{aligned}
$$

where $\zeta$ is $2 h$. It is seen that Eq.(3) - (6) are identical to Eq.(11) and (2). Indeed it is clear that there are only two independent equations. Looking at the left hand unit formed of members $\mathrm{A}\left(\mathrm{G}_{\mathrm{L}}\right)$ and $\left(\mathrm{C}_{\mathrm{L}}\right) \mathrm{F}$, we can obtain the moment 
equilibrium of each member for the pin joint D

$$
\begin{aligned}
M_{D\left(A G_{L}\right)}:-\zeta H_{A}+\lambda V_{A} & =-\zeta H_{G L}+\lambda V_{G L}, \\
M_{D\left(C_{L} F\right)}: \zeta H_{F}+\lambda V_{F} & =\zeta H_{C L}+\lambda V_{C L} .
\end{aligned}
$$

Eq.(11), (21), (7) and (8) can be expressed in matrix form which results in Eq.(9)

$$
\begin{aligned}
{\left[\begin{array}{cccc}
1 & 0 & 1 & 0 \\
0 & 1 & 0 & 1 \\
0 & 0 & \zeta & -\lambda \\
-\zeta & -\lambda & 0 & 0
\end{array}\right]\left\{\begin{array}{c}
H_{C L} \\
V_{C L} \\
H_{G L} \\
V_{G L}
\end{array}\right\} } & =-\left[\begin{array}{cccc}
1 & 0 & 0 & 0 \\
0 & 1 & 0 & 0 \\
-\zeta & \lambda & 0 & 0 \\
0 & 0 & 0 & 0
\end{array}\right]\left\{\begin{array}{c}
H_{A} \\
V_{A} \\
H_{B} \\
V_{B}
\end{array}\right\}-\left\{\begin{array}{c}
H_{D}+H_{F} \\
V_{D}+V_{F} \\
0 \\
\zeta H_{F}+\lambda V_{F}
\end{array}\right\} \\
\Leftrightarrow\left[R_{1}\right]\left\{C G_{L}\right\} & =-\left[Y_{1}\right]\{A B\}-\left\{Z_{D F}\right\} \\
\left\{C G_{L}\right\} & =-\left[R_{1}\right]^{-1}\left[Y_{1}\right]\{A B\}-\left[R_{1}\right]^{-1}\left\{Z_{D F}\right\}
\end{aligned}
$$

A similar expression can be derived for the right hand scissor unit as

$$
\begin{aligned}
& {\left[\begin{array}{cccc}
1 & 0 & 1 & 0 \\
0 & 1 & 0 & 1 \\
-\zeta & \lambda & 0 & 0 \\
0 & 0 & \zeta & \lambda
\end{array}\right]\left\{\begin{array}{c}
H_{C R} \\
V_{C R} \\
H_{G R} \\
V_{G R}
\end{array}\right\}=-\left[\begin{array}{cccc}
0 & 0 & 1 & 0 \\
0 & 0 & 0 & 1 \\
0 & 0 & 0 & 0 \\
0 & 0 & -\zeta & -\lambda
\end{array}\right]\left\{\begin{array}{c}
H_{A} \\
V_{A} \\
H_{B} \\
V_{B}
\end{array}\right\}-\left\{\begin{array}{c}
H_{E}+H_{H} \\
V_{E}+V_{H} \\
\zeta H_{H}-\lambda V_{H} \\
0
\end{array}\right\}} \\
& \Leftrightarrow\left[L_{2}\right]\left\{C G_{R}\right\}=-\left[Y_{2}\right]\{A B\}-\left\{Z_{E H}\right\} \\
& \left\{C G_{R}\right\}=-\left[L_{2}\right]^{-1}\left[Y_{2}\right]\{A B\}-\left[L_{2}\right]^{-1}\left\{Z_{E H}\right\}
\end{aligned}
$$

At the nodes $\mathrm{C}$ and $\mathrm{G}$ the external forces $V_{C}, H_{C}, V_{G}, H_{G}$ are in the equilibrium with internal forces $H_{G L}$ and $V_{C R}, H_{C R}, V_{G R}, H_{G R}$ (see Fig. 3). The sum of the forces for each separate unit can thus be expressed as

$$
\begin{gathered}
\left\{\begin{array}{c}
H_{C L} \\
V_{C L} \\
H_{G L} \\
V_{G L}
\end{array}\right\}+\left\{\begin{array}{c}
H_{C R} \\
V_{C R} \\
H_{G R} \\
V_{G R}
\end{array}\right\}=\left\{\begin{array}{c}
H_{C} \\
V_{C} \\
H_{G} \\
V_{G}
\end{array}\right\} \\
\Leftrightarrow\left\{C G_{L}\right\}+\left\{C G_{R}\right\}=\{C G\}
\end{gathered}
$$

Substituting Eq.(9) and Eq.(10) into Eq.(11) and rearranging leads to

$$
\begin{aligned}
{[P]\{A B\} } & =\{C G\}+\left[R_{1}\right]^{-1}\left\{Z_{D F}\right\}+\left[L_{2}\right]^{-1}\left\{Z_{E H}\right\} \\
\text { where, }[P] & =\left[-\left[R_{1}\right]^{-1}\left[Y_{1}\right]-\left[L_{2}\right]^{-1}\left[Y_{2}\right]\right]
\end{aligned}
$$




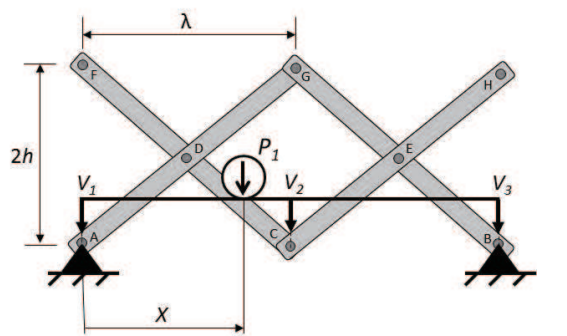

(a)

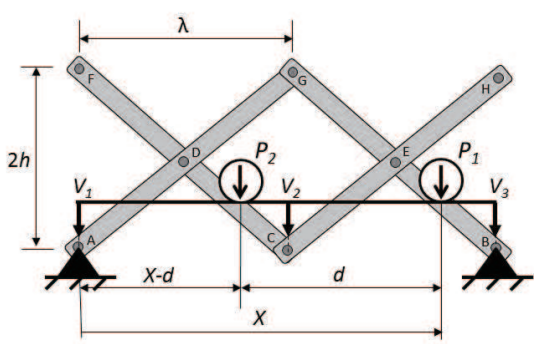

(b)

Figure 4: Theoretical models of the two scissor units structure with a traversing load. (a) Single point load. (b) Two-point load.

If the determinant of $[P]$, which is a coefficient matrix for the vector $\{A B\}$ is not 0 , the reaction forces at supports have unique (and meaningful) solutions. Moreover, if the external forces are known, then Eq.(12) can be solved directly.

\subsection{Theoretical model for scissor type bridge with a traversing load}

The above analysis is now extended to incorporate a loading that traverses the bridge. The simplified theoretical models with the loads traversing the MB1.0 are shown in Fig. 4(a) and (b). Fig. 4(a) shows a theoretical model with a single point load and the Fig. 4(b) shows a two-point load. The external nodal forces arising from vehicle loading are transmitted to the nodes of the structure via deck boards. Here, it is assumed that the nodal forces which acts on the structure only in the vertical direction can be obtained by calculating the reaction forces of the deck boards.

When a vehicle moves onto the bridge or begins to exit the structure, it makes a single point contact and in effect applies a single point load. This traversing load $P_{1}$ is located at a distance $X$ from the edge point, which is

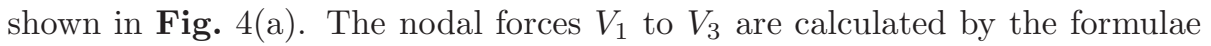
given in the Table 1

When the vehicle is fully on the bridge, it has two points of contact, creating a two-point loading as shown in Fig. 4 (b). The nodal forces $V_{1}$ to $V_{3}$ are calculated by the formulae given in the Table 2 . 
Table 1: Nodal forces for traversing single point loading.

\begin{tabular}{|c|c|c|}
\hline \multirow{2}{*}{$\begin{array}{c}\text { Nodal } \\
\text { force }\end{array}$} & $0 \leq X \leq \lambda$ & $\lambda \leq X \leq 2 \lambda$ \\
\cline { 2 - 3 } & $0 \leq$ \\
\hline$V_{1}$ & $P_{1}\left(1-\frac{X}{\lambda}\right)$ & 0 \\
$V_{2}$ & $\frac{P_{1} X}{\lambda}$ & $P_{1}\left(1-\frac{X-\lambda}{\lambda}\right)$ \\
$V_{3}$ & 0 & $P_{1}\left(\frac{X-\lambda}{\lambda}\right)$ \\
\hline
\end{tabular}

Table 2: Nodal forces for traversing two-point loading.

\begin{tabular}{|c|c|c|c|c|c|}
\hline \multirow{2}{*}{$\begin{array}{c}\text { Nodal } \\
\text { force }\end{array}$} & \multicolumn{5}{|c|}{ Section } \\
\cline { 2 - 6 } & $0 \leq X \leq d$ & $d \leq X \leq \lambda$ & $\lambda \leq X \leq \lambda+d$ & $\lambda+d \leq X \leq 2 \lambda$ & $2 \lambda \leq X \leq 2 \lambda+d$ \\
\hline$V_{1}$ & $P_{1}\left(1-\frac{X}{\lambda}\right)$ & $P_{1}\left(1-\frac{X}{\lambda}\right)+P_{2}\left(1-\frac{X-d}{\lambda}\right)$ & $P_{2}\left(1-\frac{X-d}{\lambda}\right)$ & 0 & 0 \\
$V_{2}$ & $\frac{P_{1} X}{\lambda}$ & $\frac{P_{1} X}{\lambda}+\frac{P_{2}(X-d)}{\lambda}$ & $\frac{P_{1}(2 \lambda-X)}{\lambda}+\frac{P_{2}(X-d)}{\lambda}$ & $\frac{P_{1}(2 \lambda-X)}{\lambda}+\frac{P_{2}(2 \lambda+d-X)}{\lambda}$ & $\frac{P_{2}(2 \lambda+d-X)}{\lambda}$ \\
$V_{3}$ & 0 & 0 & $\frac{P_{1}(X-\lambda)}{\lambda}$ & $\frac{P_{1}(X-\lambda)}{\lambda}+\frac{P_{2}((X-d)-\lambda)}{\lambda}$ & $\frac{P_{2}((X-d)-\lambda)}{\lambda}$ \\
\hline
\end{tabular}

It is possible to set up the equilibrium equations with traversing loads in similar way to Eq.(9) - Eq.(11). That is, nodal forces which are affected by the vehicle loading are recalculated as $V_{A} \rightarrow V_{A}-V_{1}, V_{B} \rightarrow V_{B}-V_{2}$ and $V_{C} \rightarrow V_{C}-V_{3} .\{A B\}$ and $\{C G\}$ are re-defined as $\{A B\}^{*}$ and $\{C G\}^{*}$ by the following relationships

$$
\{A B\}^{*}=\left\{\begin{array}{c}
H_{A} \\
V_{A}-V_{1} \\
H_{B} \\
V_{B}-V_{2}
\end{array}\right\}, \quad\{C G\}^{*}=\left\{\begin{array}{c}
H_{C} \\
V_{C}-V_{2} \\
H_{G} \\
V_{G}
\end{array}\right\}
$$

It is possible to find $\{A B\}$ in the same way as Eq.(12), by solving the following equations;

$$
[P]\{A B\}^{*}=\{C G\}^{*}+\left[R^{1}\right]^{-1}\left\{Z_{D F}\right\}+\left[L^{2}\right]^{-1}\left\{Z_{E H}\right\}
$$

This analysis enables the calculation of the nodal forces which are acting on the bridge under the traversing load. 


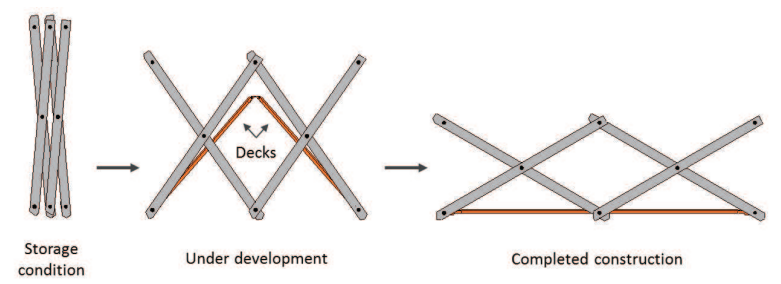

(a)

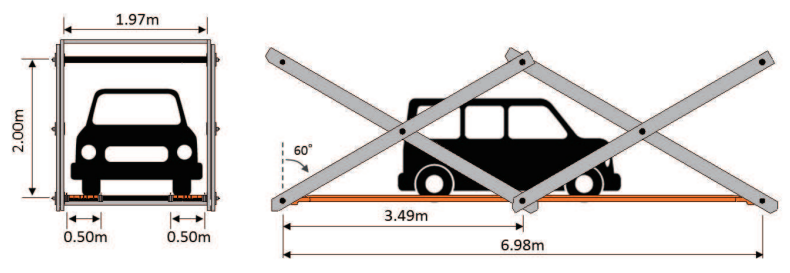

(b)

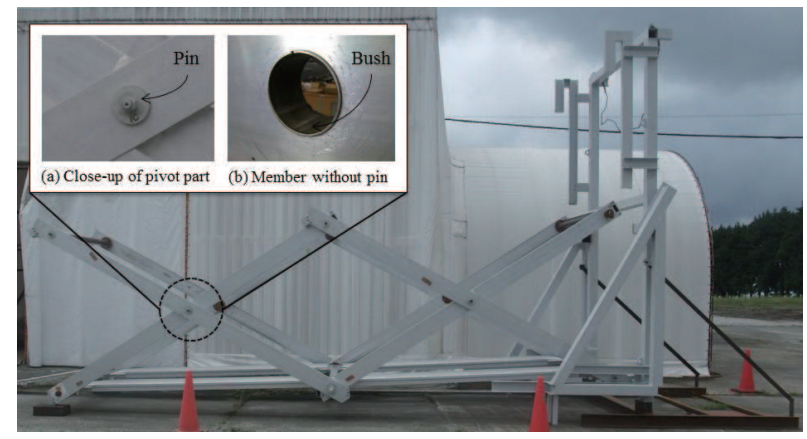

(c)

Figure 5: The schematic of the experimental MB1.0. (a) Expanding of the bridge with deck boards. (b) In-service state. (c) The real MB1.0 and detail of a pivot part.

\section{Vehicle loading test on the full-scale Mobile Bridge}

In this section, we carry out static vehicle loading test using a full-scale 135 Mobile Bridge, MB1.0. The aim of this experiment is to assess the potential of a bridge with the scissor mechanism with a vehicle load.

\subsection{Outline of the experimental bridge}

The schematic view of the MB1.0 is presented in Fig. The MB1.0 is a two scissor units and a lower deck bridge where the transit surface is aligned with 
Table 3: Condition of the measurements for strain values.

\begin{tabular}{|c|c|c|}
\hline Position & Loading position & Points of focus \\
\hline$A$ & Centre of the first deck board & Front Wheel \\
$B$ & Centre of the first deck board & Middle of the vehicle \\
$C$ & Centre of the bridge & Front Wheel \\
$D$ & Centre of the bridge & Middlle of the vehicle \\
$E$ & Centre of the bridge & Rear Wheel \\
\hline
\end{tabular}

the line of lower hinges. Fig. 5(a) shows the bridge deployment from its stored state to the complete expansion. Once fully constructed in the in-service state, the bridge will allow for traffic to traverse, which is shown in Fig. 5(b). Upon achieving the fully extended form the bridge is simply supported. The MB1.0 is equipped with a foldable deck boards which follows the process of deployment. At full extension the total length of the span is $7.0 \mathrm{~m}$ and the height is $2.0 \mathrm{~m}$. The total dead weight of the MB1.0 including all parts is $8.6 \mathrm{kN}$.

All scissor members are connected by iron pins and shafts in each hinge part. There are bush materials between holes in scissors members and jointing parts reducing frictions (See Fig. 5(c)). The main members of the main frame and the deck boards are made of extruded aluminum alloy to reduce the dead load of the structure. The members of the main frame are made from aluminium alloy A6N01 and the deck is made of alloy A6063. The sectional properties of the main frame components, which are made using A6N01, are $A=28.0 \mathrm{~cm}^{2}, I=1146.3 \mathrm{~cm}^{4}$. The material properties of the A6N01 are: $E=62.5 \mathrm{GPa}$ and $\sigma_{y}=180.0 \mathrm{MPa}$. The sectional properties of deck boards are $A=30.4 \mathrm{~cm}^{2}, I=182.7 \mathrm{~cm}^{4}$. The material properties of the A6063 are: $E=68.0 \mathrm{GPa}$ and $\sigma_{y}=110.0 \mathrm{MPa}$. The width of the deck boards is kept to a minimum in order to reduce the mass and it slightly larger than the width of the tyre of the vehicle.

\subsection{Outline of the vehicle loading test}

In this section, conditions of the experiments are described. 


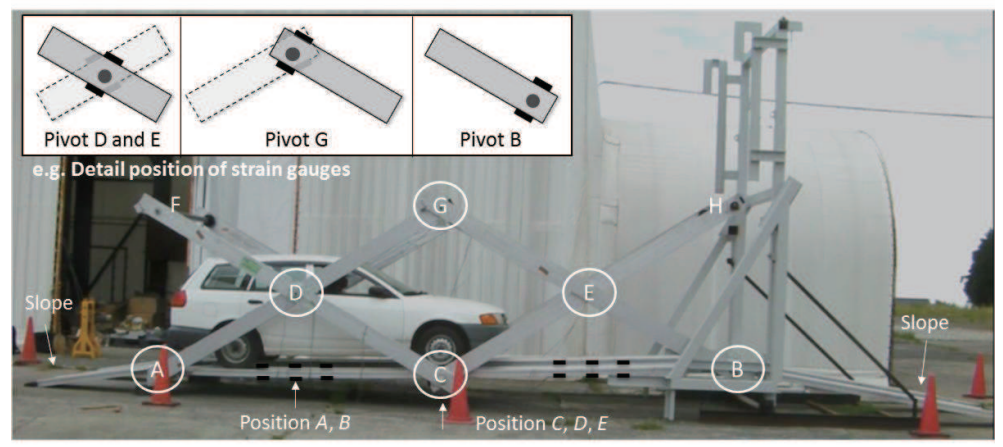

Figure 6: Experimental setup of the MB1.0 with AD Van.

\subsubsection{Measurement methods and measured points}

In the vehicle loading test, strain values which occur when the vehicle passes the bridge are measured. We focused on two critical positions of the vehicle on the bridge which is the centre of the deck board of the first unit and the middle of MB1.0. The measurements were performed for five cases in order to evaluate the change of static strain values with respect to the vehicle locations, shown in the Table 3, In the positions $A$ and $B$, the front wheel and the middle of the vehicle are placed in the centre of the deck board respectively, in the position $C$ - $E$, the front wheel, the middle of the vehicle and the rear wheel are positioned in the middle of the MB1.0 respectively.

Fig. 6 shows the experimental setup and points measured by single strain gauges having the length of $5 \mathrm{~mm}$ when the front wheel of the vehicle is in the middle of the MB1.0. Here, each nodal name is defined from $\mathrm{A}$ to $\mathrm{H}$ in the same way as the section 2. The strain gauges are located on the upper and lower surface of the members at pivot $\mathrm{D}$ and $\mathrm{E}$, and hinge-connection $\mathrm{A}, \mathrm{B}, \mathrm{C}$ and G (see Fig. 6). Furthermore, in order to evaluate the influence of deck boards, the strain gauges are located on the upper and lower surface in the centre of each deck boards and at positions shifted from their centre by $\pm 800 \mathrm{~mm}$. Every strain gauge for members and deck boards is set on its central axis in longitudinal direction. 
Table 4: Loading conditions

\begin{tabular}{|c|c|c|c|c|}
\hline \multirow{2}{*}{$\begin{array}{c}\text { Loading } \\
\text { case }\end{array}$} & Vehicle & \multicolumn{3}{|c|}{ Loading conditions(kN) } \\
\cline { 3 - 5 } & type & Total & Front axle & Rear axle \\
\hline 1 & Light vehicle (STREET) & 9.6 & 5.2 & 4.4 \\
2 & Light vehicle (STREET) & 11.8 & 6.3 & 5.5 \\
3 & Ordinary vehicle (AD Van) & 13.8 & 7.5 & 6.3 \\
\hline
\end{tabular}

\subsubsection{Loading conditions}

Two kinds of vehicles, STREET and AD van, were used for the loading test. The STREET is a light vehicle and the AD van is a standard-sized car. The STREET's length $\times$ width $\times$ height is $3195 \times 1395 \times 1870 \mathrm{~mm}$, while the $\mathrm{AD}$ van's length $\times$ width $\times$ height is $4370 \times 1895 \times 1510 \mathrm{~mm}$. The loading conditions including total and axel weights are summarized in the Table 4. The Case 1 and 2 refer to the STREET car with the total weight of $9.6 \mathrm{kN}$ and $11.8 \mathrm{kN}$, and the Case 3 describes the $\mathrm{AD}$ van with the total weight of is $13.8 \mathrm{kN}$ including the weight of a driver. The Case 1 differs from the Case 2 only by the total load of the car while the Case 3 includes also extended wheel base.

\subsection{Results of the experiment}

\subsubsection{Distribution of the strain values - vehicle at the centre of the MB1.0}

Figs. 7 (a) - (c) show the distribution of the strain values when the vehicle is at the Position $D$ which is the centre of the MB1.0. Fig. 7(a) depicts the measurement results for the two structural members AG and BG in ' $\Lambda$ '-shaped form, which contact the supports, Fig. (7)(b) depicts the measurement results of 'V'-shaped two members $\mathrm{CF}$ and $\mathrm{CH}$ with ends in free boundary condition and Fig. I(c) depicts the measurement results of the deck boards. The horizontal axis shows the position of the strain gauges measured from the gate and the vertical axis shows the strain values. Moreover, the presented members and deck boards are colored in red. The black marks in the figures show the positions of the strain gauges. 


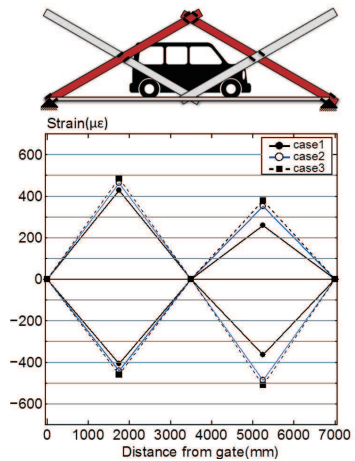

(a)

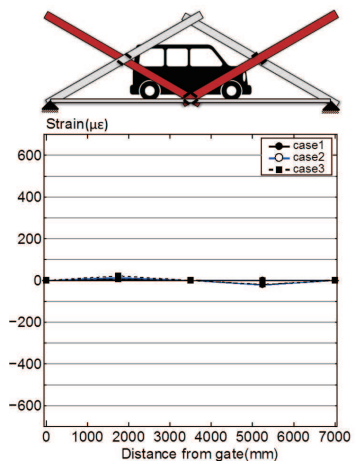

(b)

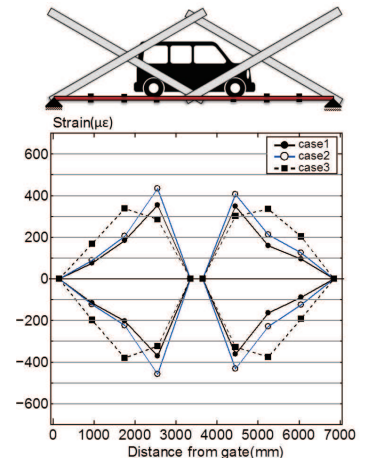

(c)

Figure 7: Distribution of strain values when the vehicle is at the Position $D$ in the centre of the MB1.0. (a) ' $\Lambda$ '-shaped member. (b) 'V'-shaped member. (c) Deck boards.

From Fig. [7(a), we can see that the maximum and minimum strain of about $500 \mu \epsilon$ occurred at the pivot on the lower edge of the first unit and the upper edge

205 
ends, they transmit mainly tensile force caused by the loading of the vehicle. This shows that in the MB1.0 ' $\Lambda$ '-shaped elements play the most important role in bearing the load.

Fig. 7(c) shows that the strains which occurred in the deck boards were almost equal in the compression and tension region. In other words, this symmetry means that for the deck boards the influence of the axial force is much lower than of the bending moment.

\subsubsection{Change of the edge strain values under a moving load}

Fig. 8 and Fig. 9 show the change of edge strain values at each pivot in the ' $\Lambda$ '-shaped members. Fig. 8 shows the results of using the STREET car and Fig. 9 shows the results of using the AD Van. The horizontal axis denotes the position of the front wheel measured from the gate and the vertical axis denotes the edge strain values.

235 In each experiment, the edge strain values were getting larger as the vehicle approached the centre of the bridge (Position $A-C$ ). The maximum value was attained with the vehicle stationary at the centre (Position $D$ ). When we focus our attention on the distribution profile of the edge strain values, it turns out that in the first unit the bending moment is combined with the tensile force and in the second unit the bending moment is combined with the compressive force. These differences are a result of non-perfect boundary conditions such as inclination of the MB1.0 (see Figs. 6).

Another difference arises from dissimilarity of the wheel base distance for each vehicle. Increase of the vehicle weight of $18.6 \%$ between the Case 1 and the Case 2 causes increase of the maximum edge strain values by average $17.1 \%$ (see Fig. 8). When we compare the maximum edge strain values between the Case 2 and the Case 3, the maximum edge strain values increase by $5.5 \%$ (see Fig. 8 and Fig. 9) with the vehicle weight increased by $14.5 \%$. 


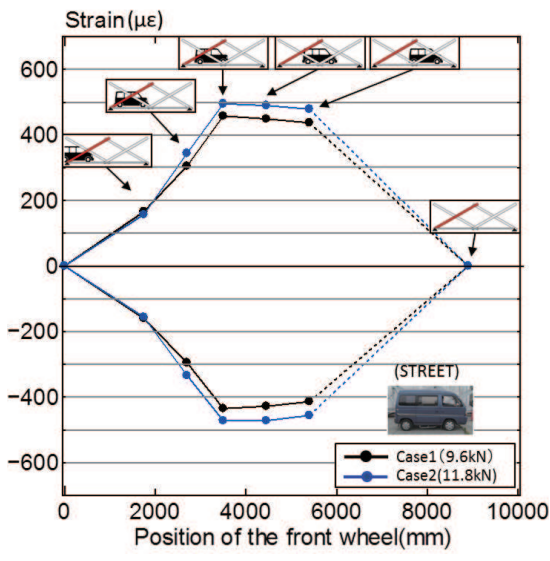

(a)

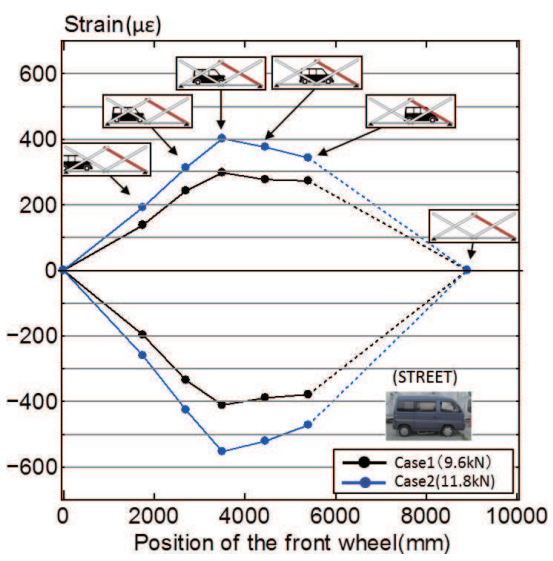

(b)

Figure 8: Change of the edge strain values at each pivot for STREET car. (a) The first unit.

(b) The second unit.

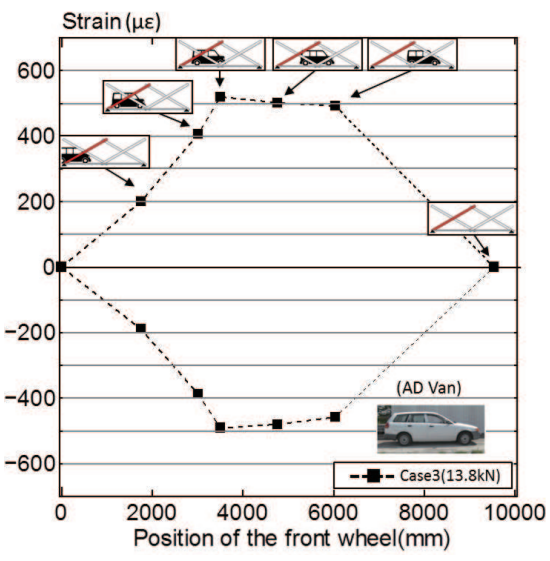

(a)

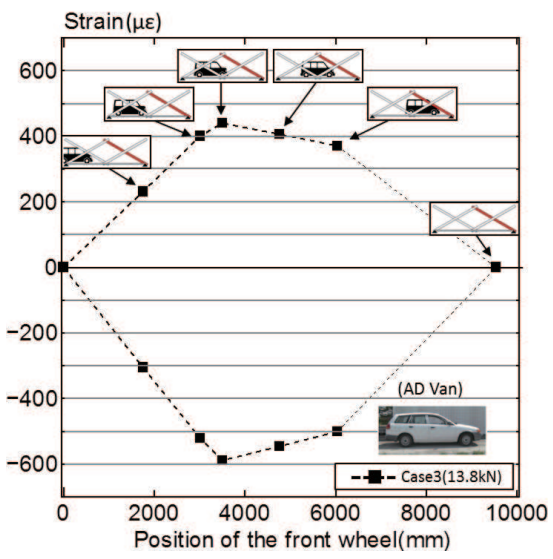

(b)

Figure 9: Change of the edge strain values at each pivot for the AD Van. (a) The first unit. (b) The second unit. 


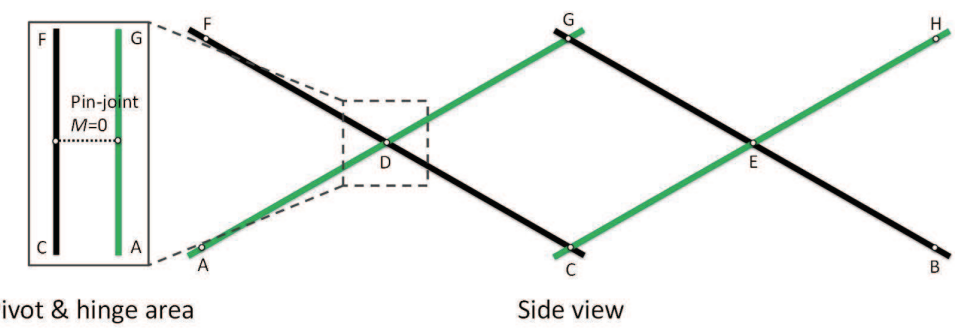

Figure 10: Outline of the FE numerical model of the MB1.0.

Table 5: FE numerical models of the MB1.0.

\begin{tabular}{|c|c|c|c|}
\hline FE numerical model & $(1)$ & $(2)$ & $(3)$ \\
\hline Deck boards & Between AC and BC & Between AC and BC & No deck boards \\
\hline Boundary conditions & Both-ends pin supports & Pin and roller supports & Both-ends pin supports \\
\hline
\end{tabular}

\section{FE numerical model based on FEM}

\subsection{Description of the model}

Finite element model of the bridge is based on its experimental version MB1.0 presented in this paper and was created by means of the structural analysis software ABAQUS 6.12. The outline of the FE numerical model is shown in Fig. 10. In this simulation, we used linear beam elements and considered 255 a simplified 2D model due to the symmetry of the MB1.0. In order to model pivots and hinges, each scissor member is connected by the joint elements which do not transfer any bearing.

We investigate the mechanical characteristics of the MB1.0 by using three slightly different FE numerical models as shown in the Table 5. We examine

the influence of deck boards by defining two groups of models - with and without them. In each group, we consider the effect of different boundary conditions i.e. double pin supports and pin-roller supports.

For each FE numerical model analyses were performed for positions of the vehicle according to the Table 3. In the models with deck boards, the wheel loads were acting directly on the deck boards. In case of the model without deck 


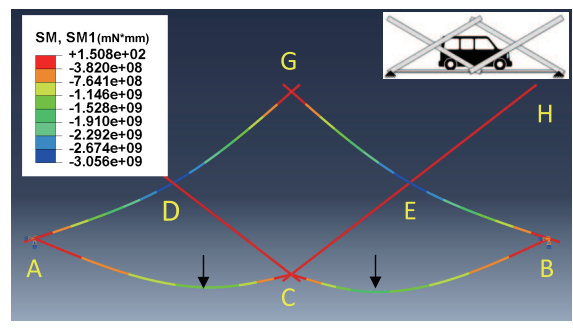

(a)

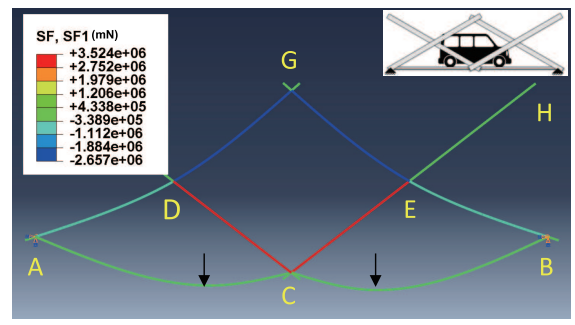

(b)

Figure 11: Distribution of the sectional forces for FE numerical model (1) when vehicle loaded on the central MB1.0. (a) Distribution of bending moments. (b) Distribution of axial forces.

Table 6: Stress values related at bending moment at point D in the member AG and related to axial force at point $\mathrm{D}$ in the member $\mathrm{AD}$.

\begin{tabular}{|c|c|c|c|c|c|c|}
\hline $\begin{array}{c}\text { Model } \\
\text { (B.C.) }\end{array}$ & \multicolumn{2}{|c|}{$\begin{array}{c}\text { (1) Deck boards } \\
\text { (Both-ends pin supports) }\end{array}$} & $\begin{array}{c}\text { (2) Deck boards } \\
\text { (Pin and roller supports) }\end{array}$ & \multicolumn{2}{c|}{$\begin{array}{c}\text { (3) Without deck boards } \\
\text { (Both-ends pin supports) }\end{array}$} \\
\hline Stress(MPa) & $\left|\sigma_{\mathrm{M}_{\mathrm{D}}(\mathrm{AG})}\right|$ & $\left|\sigma_{\mathrm{N}_{\mathrm{AD}}}\right|$ & $\left|\sigma_{\mathrm{M}_{\mathrm{D}(\mathrm{AG})} \mid}\right| \sigma_{\mathrm{N}_{\mathrm{AD}}} \mid$ & $\left|\sigma_{\mathrm{M}_{\mathrm{D}(\mathrm{AG})} \mid}\right| \sigma_{\mathrm{N}_{\mathrm{AD}}} \mid$ \\
\hline Position $A$ & 9.6 & 0.12 & 9.7 & 0.12 & 9.9 & 0.12 \\
Position $B$ & 18.6 & 0.23 & 18.8 & 0.24 & 19.2 & 0.22 \\
Position $C$ & 27.3 & 0.32 & 27.3 & 0.33 & 27.5 & 0.32 \\
Position $D$ & 26.5 & 0.31 & 26.7 & 0.31 & 26.7 & 0.31 \\
Position $E$ & 25.9 & 0.29 & 26.1 & 0.29 & 25.9 & 0.30 \\
\hline
\end{tabular}

boards, the reaction forces of the real decks were transferred as the equivalent nodal forces to points $\mathrm{A}, \mathrm{B}$ and $\mathrm{C}$ of the main frame.

\subsection{Comparison of the results of three FE numerical models}

Fig. 11]presents distribution of bending moments and axial forces in loading case with the STREET car $(9.6 \mathrm{kN})$ positioned at the centre of the MB1.0, modeled with the deck boards and both pin supports. The maximum bending moment occurs at pivots of ' $\Lambda$ '-shaped members and the maximum axial force is present in the bottom parts of the ' $\mathrm{V}$ '-shaped members of the bridge. From these maps of sectional forces, we can see that they are symmetrically-distributed.

Stress values related to bending moment at point D in the member AG and related to axial force at point $\mathrm{D}$ in the member $\mathrm{AD}$ under loading by the STREET car $(9.6 \mathrm{kN})$ are summarized in Table 6. From this results, it 


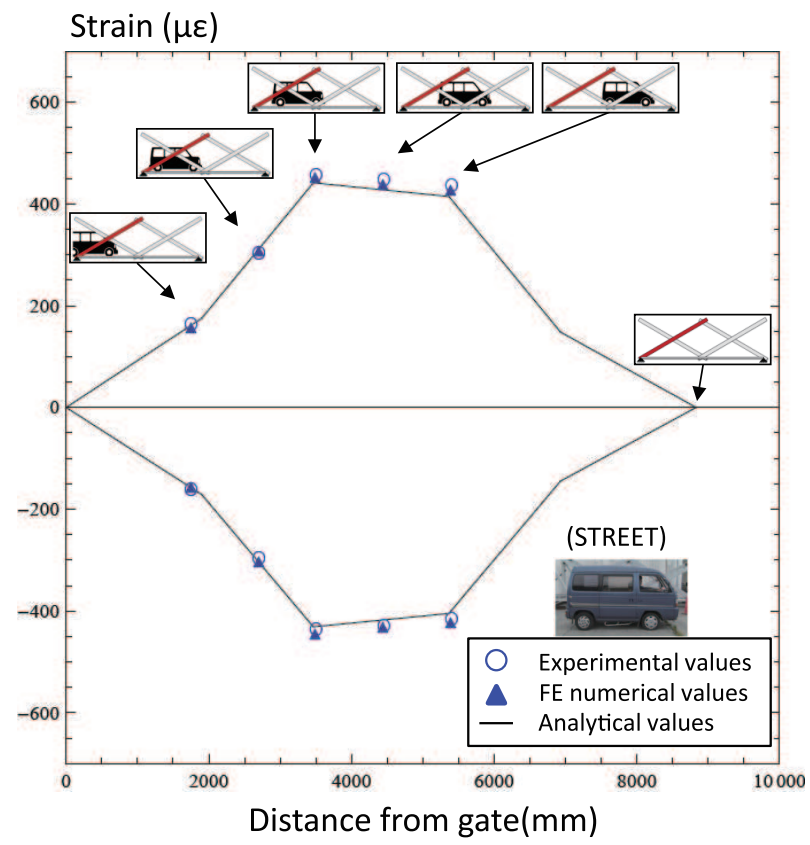

Figure 12: Comparing the edge strain distributions at point D among experimental, FE numerical and analytical values using the STREET car $(9.6 \mathrm{kN})$

visible that maximum values for both bending and axial stresses is obtained in the Position $C$, when the front wheel of the vehicle stops in the middle of the MB1.0. Furthermore, it is clear that the influence of the axial stresses in the MB1.0 are less than $2 \%$ comparing to the values of the bending stresses, which are dominant in the scissor structure, just like in the case of experimental results.

When the models (1) and (3) are compared, the difference in the stress levels is less than $4 \%$. When we compare with the effect of different boundary conditions, although the sectional forces of pin and roller supports model are little higher than in the pin supports model, the difference in stresses does not exceed $1 \%$.

As a conclusion, we can state that there is no significant effect of the deck boards and support conditions on internal stresses in the MB1.0. Moreover, if a simplified FF numerical model is required, it is sufficient to consider only scissor 
Table 7: Detailed comparison of the edge strain values at point $\mathrm{D}$ with each loading position.

\begin{tabular}{|c|c|c|c|c|c|c|}
\hline \multirow{2}{*}{$\begin{array}{c}\text { Loading } \\
\text { position }\end{array}$} & \multicolumn{2}{|c|}{ Experimental strain } & \multicolumn{2}{c|}{ FE numerical strain } & \multicolumn{2}{c|}{ Theoretical strain } \\
\cline { 2 - 7 } & Tension & Compression & Tension & Compression & Tension & Compression \\
\hline Position $A$ & 166 & -160 & 159 & -155 & 161 & -158 \\
Position $B$ & 305 & -295 & 309 & -301 & 311 & -304 \\
Position $C$ & 458 & -435 & 453 & -442 & 441 & -430 \\
Position $D$ & 449 & -428 & 440 & -429 & 427 & -417 \\
Position $E$ & 437 & -414 & 430 & -420 & 408 & -398 \\
\hline
\end{tabular}

members model without including the deck boards.

\section{Comparison of analytical and FE numerical models with experi- mental results}

Fig. 12 shows the summary of the strains at the upper and lower edge of the ' $\Lambda$ '-shaped member $A G$ in the vicinity of the pivot obtained for analytical, FE numerical models and in experimental results for different positions of the STREET car $(9.6 \mathrm{kN})$. Table 7 shows the detailed strain values with each loading position.

When we compare analytical and FE numerical results, it is clear that there is not much difference in calculated strain values. The maximum error is approximately $5.5 \%$ at the Position E. The obtained similar strain distribution ensures that the simple theoretical model replicates well the more advanced FE model of the MB1.0.

Comparison between the FE numerical and experimental results shows that it was possible to obtain the accuracy of maximum and minimum strain values below $5 \%$ and on the safe side. It is considered that the main cause of small errors is the method of modelling of the pivot and hinge parts. The connections of each scissor member are treated as perfect and cannot predict stress concentrations or effects related to friction. Furthermore, comparison between the theoretical and experimental results shows that there is a small error of $7 \%$ at the Position $E$. 
The above results clearly show that it is possible to have an approximate design for the full-scale MB even by means of simple frame models which does not include deck boards. That is to say, although we focused solely on the operational state and did not consider the deployment process itself, it is considered that stress or strain in the deployed state would be predictable by use of this proposed design method.

\section{Conclusions}

This paper has presented the full-scale Mobile Bridge with a lower deck boards and a light vehicle loading test. In the operational state, we succeeded to demonstrate that the strength of the bridge is viable for use as an emergency bridge for the passing of vehicles. Furthermore, a simplified design using FE numerical models based upon the experimental work demonstrated the efficacy of the method with the numerical results consistency with the results obtained from experimental testing. Based on the presented research results, the following conclusions can be drawn.

1) With a maximum loading weight of $13.6 \mathrm{kN}$, the main frame and the deck boards are within admissible stress levels, and it turns out that the vehicle with weight of $10 \mathrm{kN}$ can pass safely on the MB1.0.

2) When we compare results of three FE numerical models, there is less than 4 $\%$ difference within the edge strain values. That is to say, if we analyse or design the Mobile Bridge in simplified way, it is sufficient to consider the loading applied directly as nodal forces and without including the stiffness of the deck boards.

3) We find that the experimental strain changes are consistent with the FE numerical model with differences less than $5 \%$ on the safe side.

4) It is possible to build the simple theoretical model of the MB1.0 with moving load providing error estimated as less than $7 \%$ at most when compared with experimental values. 


\section{Acknowledgments}

This research was supported for Dr. I. Ario by a Grant-in-Aid-ScientificResearch Base Research (B) of Japan Society for the Promotion of Science (JSPS) in 2011 - 2013. We appreciated that all manufacture of cradles and experimental bridge were supported by Akashin Corporation in Japan. Moreover, we appreciated that a sample of the aluminum materials of scissor members and the deck boards were offered by Hoshi-kei-kinzoku Industry Co., Ltd. and Sankyo Tateyama, lnc Sankyo Material Co., in Japan.

\section{References}

[1] E. P. Pinero, Three Dimensional Reticular Structure, United States Patent $3,185,164,1965$.

[2] T. R. Zeigler, Collapsible Self-supporting Structure, United States Patent $3,968,808,1976$.

[3] F. Escrig, Design of Expandable Special Grids, IASS NIladrid, Vol. 4, 1989.

[4] Y. Hahawa, M. Saitoh, A. Okada and N. Miyasato, Basic Study on Structural Characteristics of String Scissors Structure, Part1 Proposal of String Scissors Structure and Possibility of PS Introduction, Summaries of technical papers of annual meeting Architectural Institute of Japan, 2001 (in Japanese).

[5] B. Glisic, A. Sigrid and S. Peter, Structural analysis and validation of a smart pantograph mast concept, Computer - Aided Civil and Infrastructure Engineering, Vol. 28. Issue 9, pp. 651-665, 2013. doi: 10.1111/mice.12013

[6] Z. You, S. Pellegrino, Foldable bar structures, International Journal of Solids and Structures, Vol. 34, Issue 15, pp. 1825-1847, 1997.

[7] A. P. Thrall, S. Adriaenssens, I. Paya-Zaforteza and T. P. Zoli, Linkage-based movable bridges: Design methodology and three 
novel forms, Engineering Structures, Vol. 37, pp. 214-223, 2012. doi:10.1016/j.engstruct.2011.12.031

[8] M. L. Clevettand, R. H. Lowdermilk, J. K. Bright, C. S. Coulter and T. W. Melton, Expandable portable bridge structure, United States Patent 4, $628,560,1986$.

[9] B. R. Russell and A. P Thrall, Portable and rapidly deployable bridges: Historical perspective and recent technology developments, Journal of Bridge Engineering, Vol. 18, Issue 10, pp. 1074 - 1085, 2013. doi: 10.1061/(ASCE)BE.1943-5592.0000454

[10] J. H. Joiner, One more river to cross: The story of British military bridging, Pen and Sword Books, South Yorkshire, U.K, 2001.

[11] I. Ario, Structure with the expanding and folding equipment as a patent (No.2006-037668) registered in 2012, Japan.

[12] I. Ario, Y. Tanaka, M. Nakazawa, Y. Furukawa and Y, Chikahiro, Development of the prototype of a new emergency bridge based on the concept of optimized structure, J. of Structural Engineering, JSCE, Vol. 64A, pp. 1-12, 2012 (in Japanese).

[13] J. Holnicki-Szulc (Ed.), Smart Technologies for Safety Engineering, Wiley, 2008.

[14] P. Pawlowski, C. Graczykowski, J. Holnicki-Szulc, I. Ario, Smart, deployable skeletal structures for safety engineering, The proceedings of the 6th ECCOMAS Thematic Conference on Smart Structures and Materials, pp. 1-10, Italy, 2013.

390

[15] I. Ario, M. Nakazawa, Y. Tanaka, I. Tanikura and S. Ono, Development of a prototype deployable bridge based on origami skill, Automation in Construction, Vol. 32, pp. 104-111, 2013. doi: 10.1016/j.autcon.2013.01.012 
[16] M. Nakazawa and I. Ario, Structural Characteristics of Scissors typeEmergency Bridges, 5th Australian Small Bridges Conference, Australia, 2012 .

[17] Y. Chikahiro, I. Ario, M. Nakazawa, S. Ono, J. Holnicki-Szulc, P. Pawlowski and C. Graczykowski, An experimental study on the design method of a full-scale Mobile Bridge for a moving vehicle, The proceedings of 4th International Conference on Mobile, Adaptable and Rapidly Assembled Structures, pp. 94-103, Belgium, 2014. doi: 10.2495/MAR140081 Conference 
(a) Close-up of pivot part

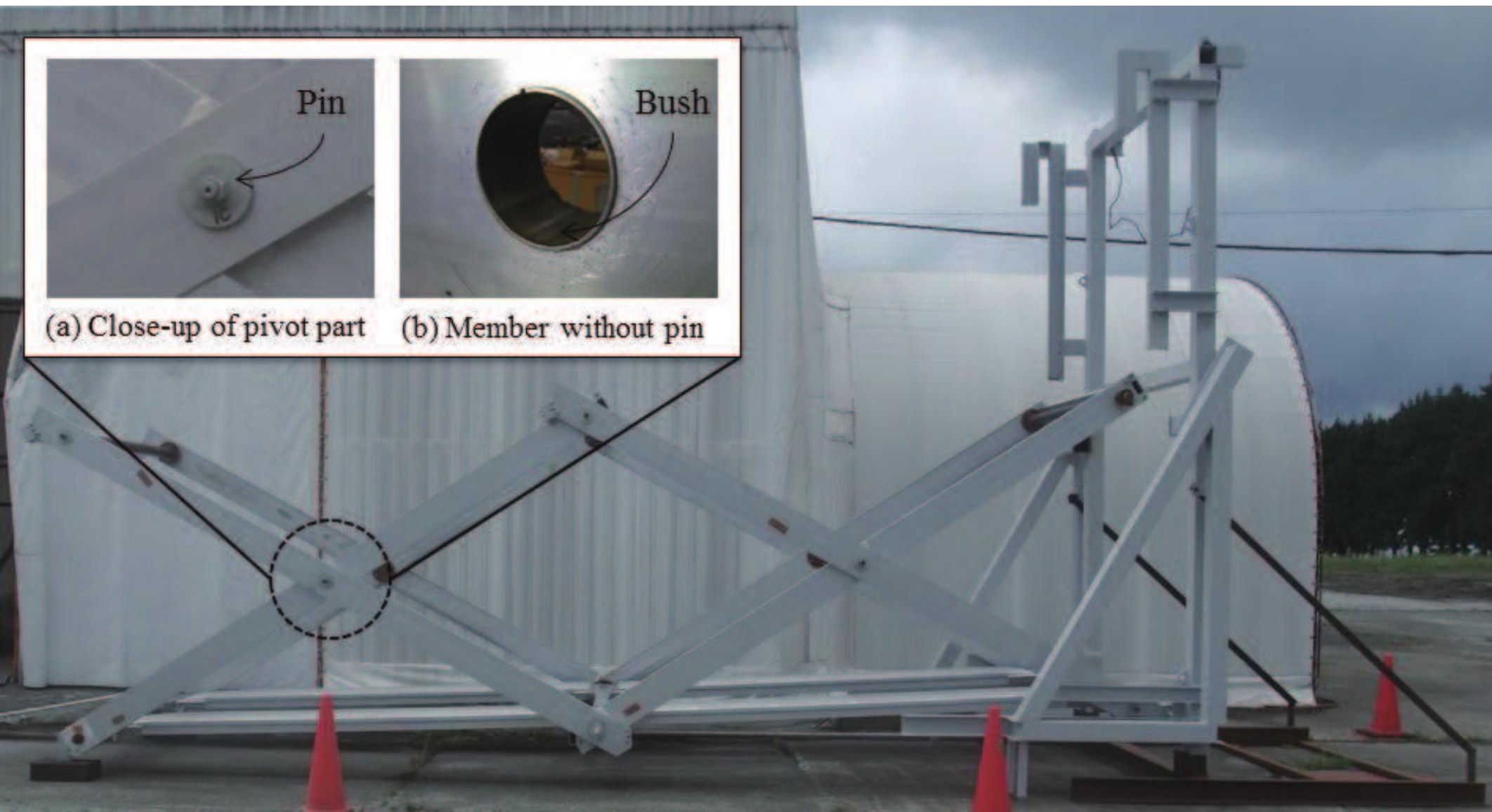

(b) Member without pin
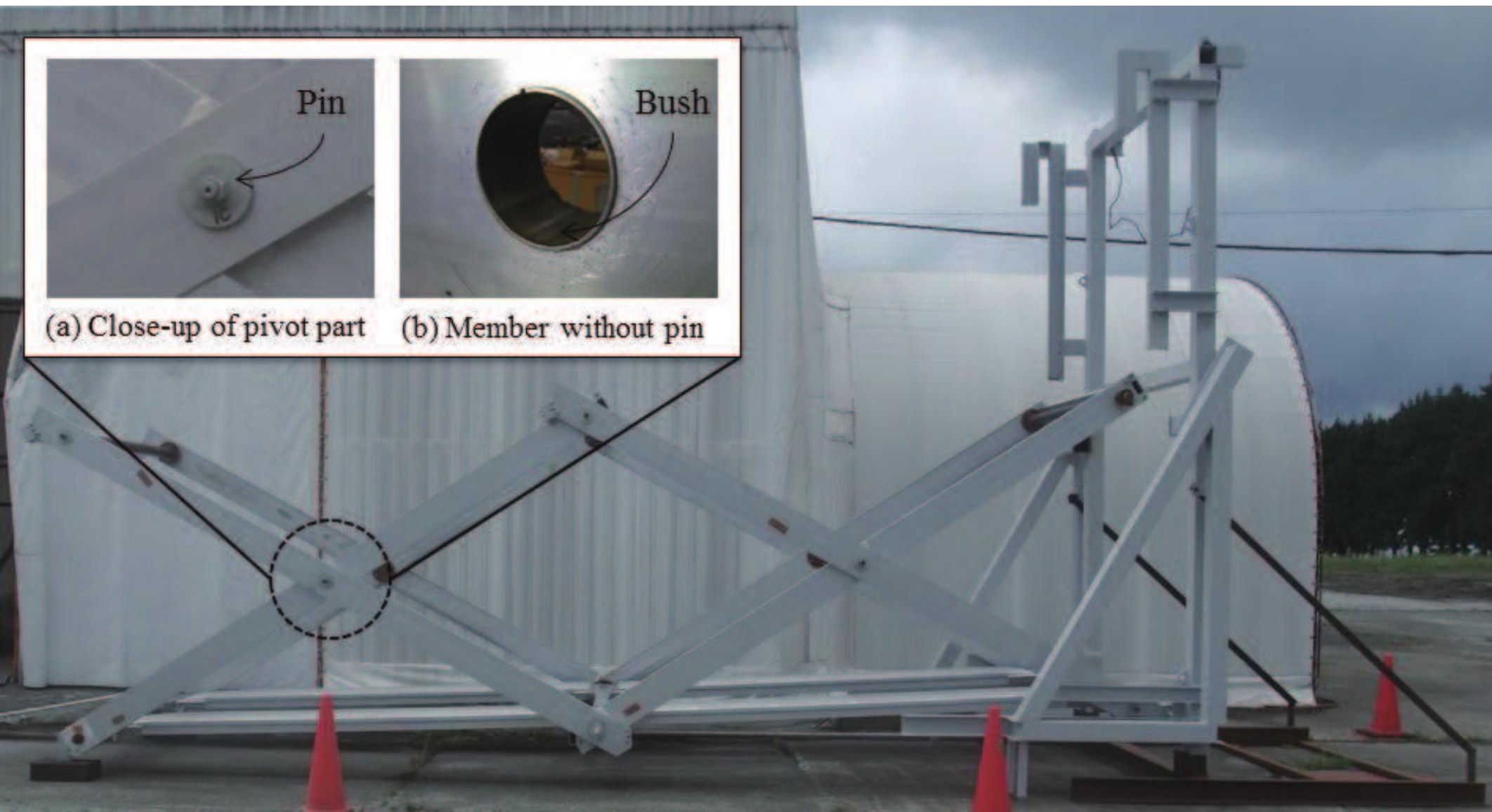

Fig. 5(c) 
Fig.11(b)

SF, SF1 $(\mathrm{mN})$

$+3.524 \mathrm{e}+06$

$+2.752 \mathrm{e}+06$

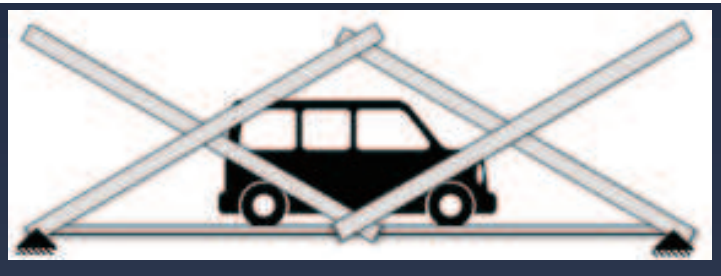

$+1.979 e+06$

$+1.206 \mathrm{e}+06$

$+4.338 e+05$

$-3.389 e+05$

$-1.112 e+06$

$-1.884 e+06$

$-2.657 e+06$ 
$\mathrm{SM}, \mathrm{SM} 1\left(\mathrm{mN}^{*} \mathrm{~mm}\right)$
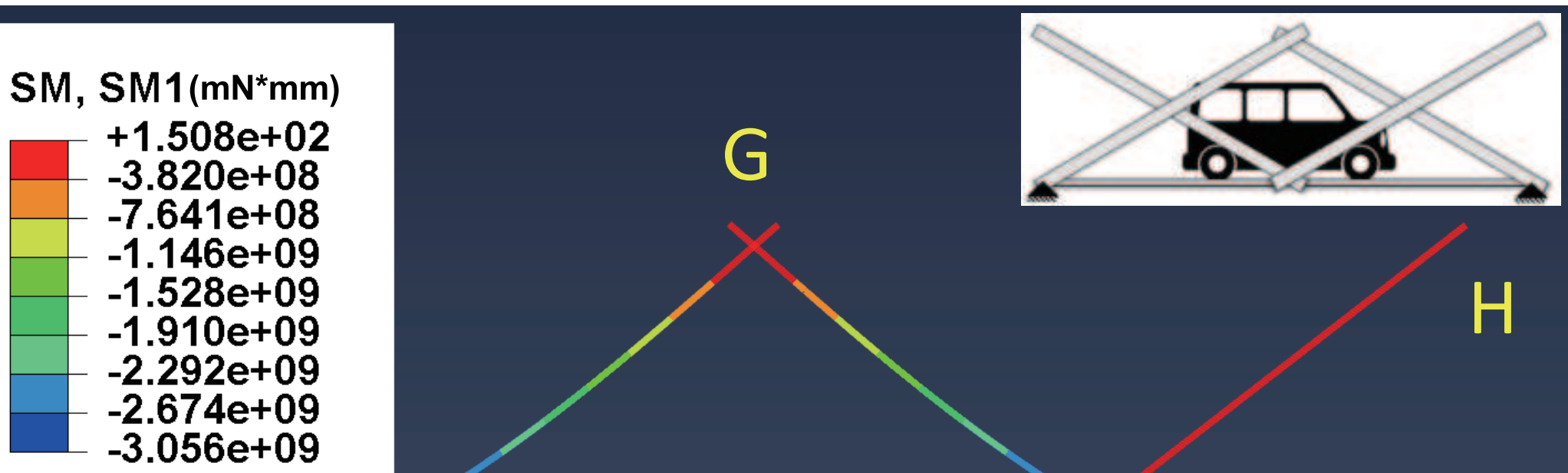

\section{$\mathrm{H}$}


Strain $(\mu \varepsilon)$

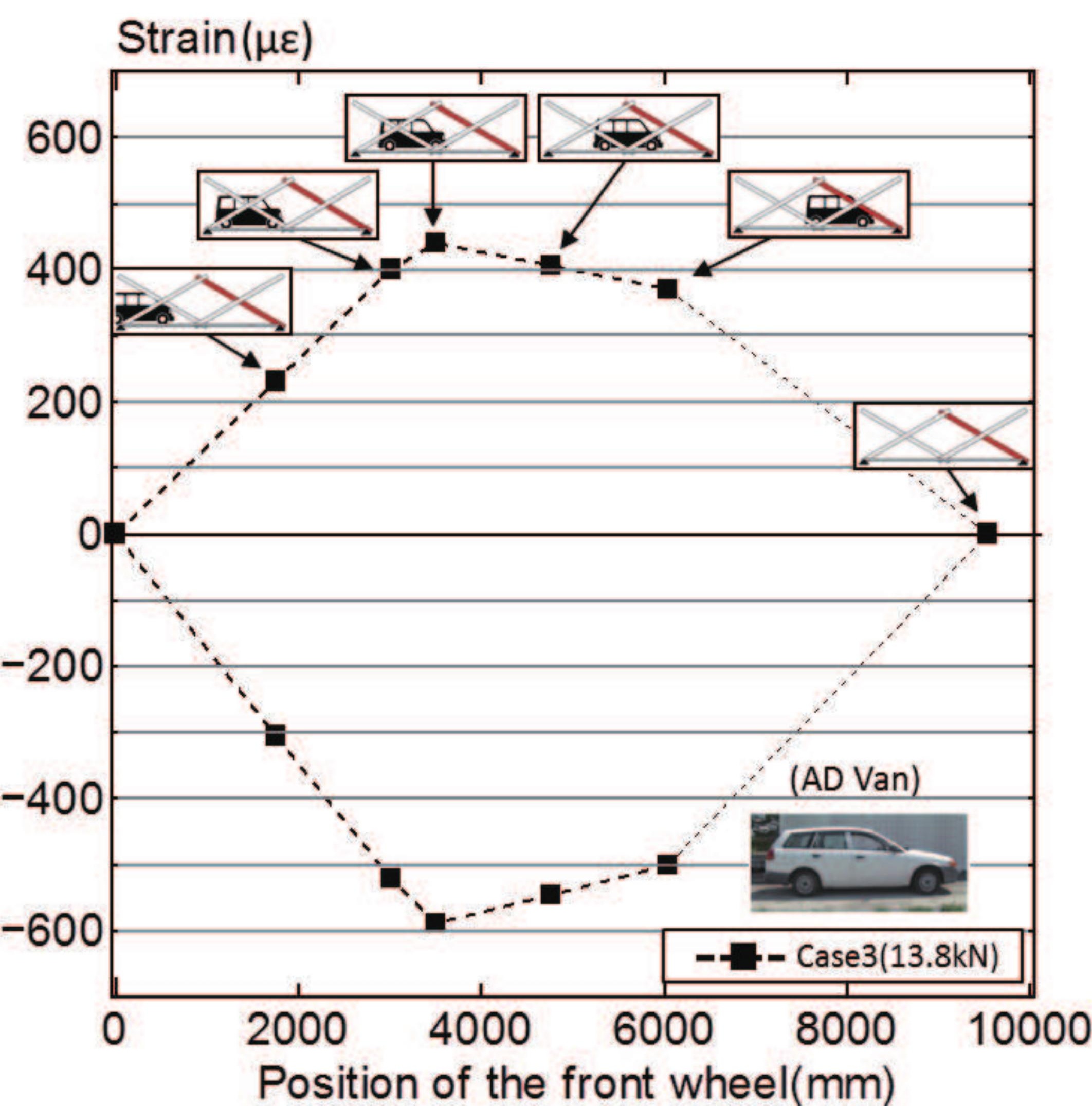

Fig. 8(a)
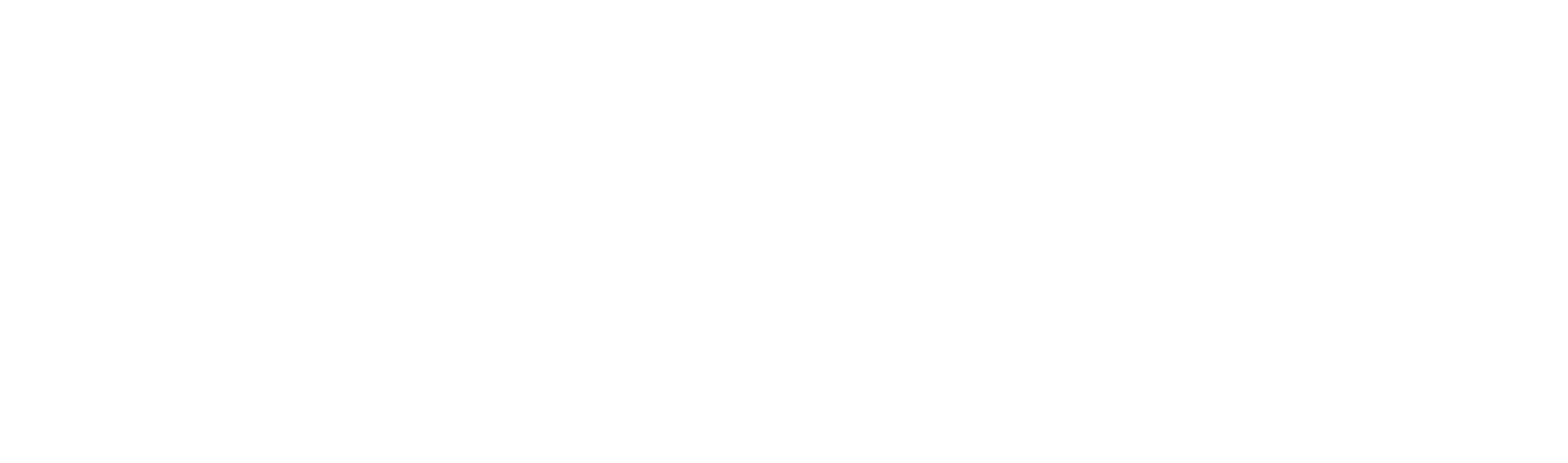

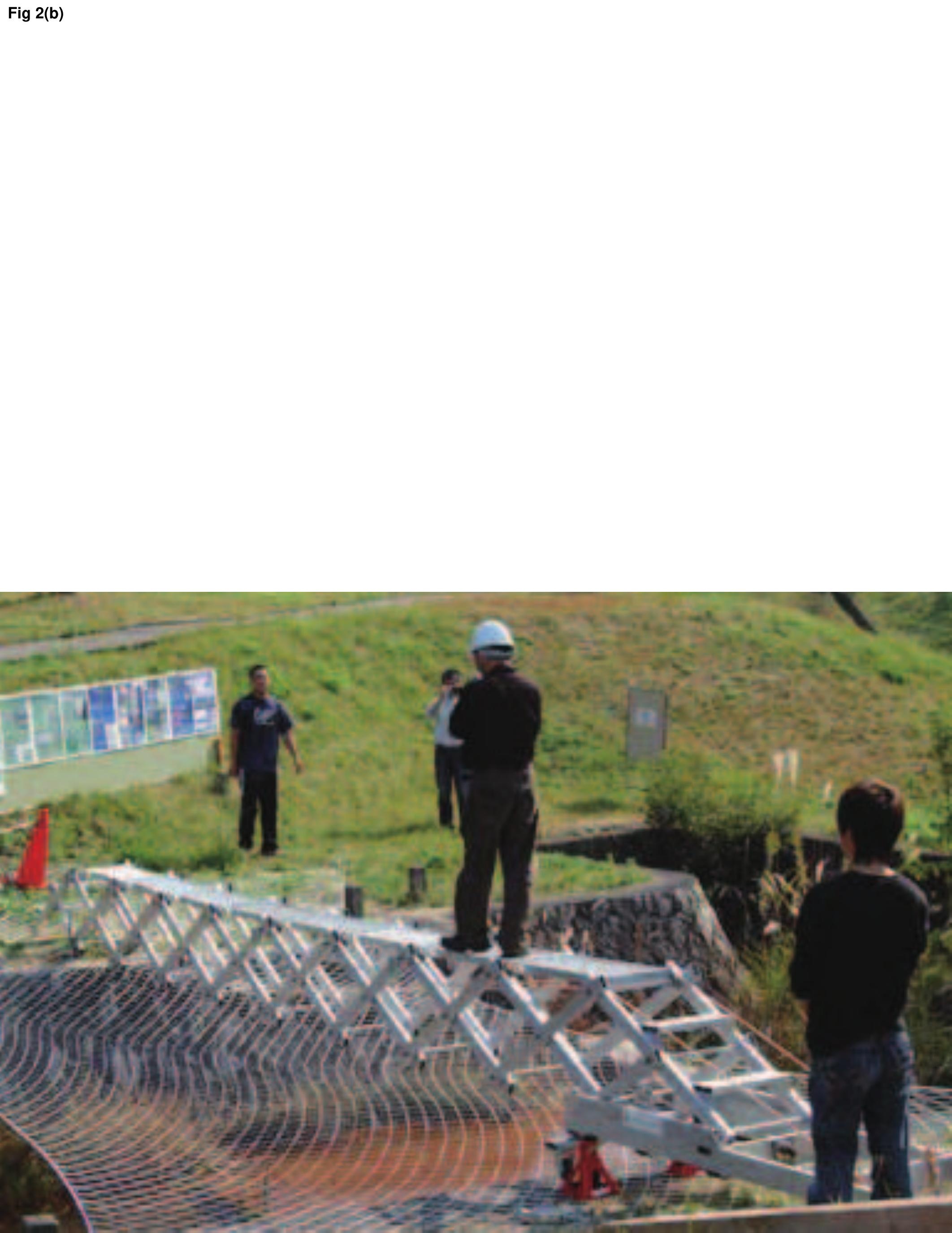

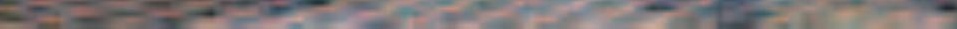

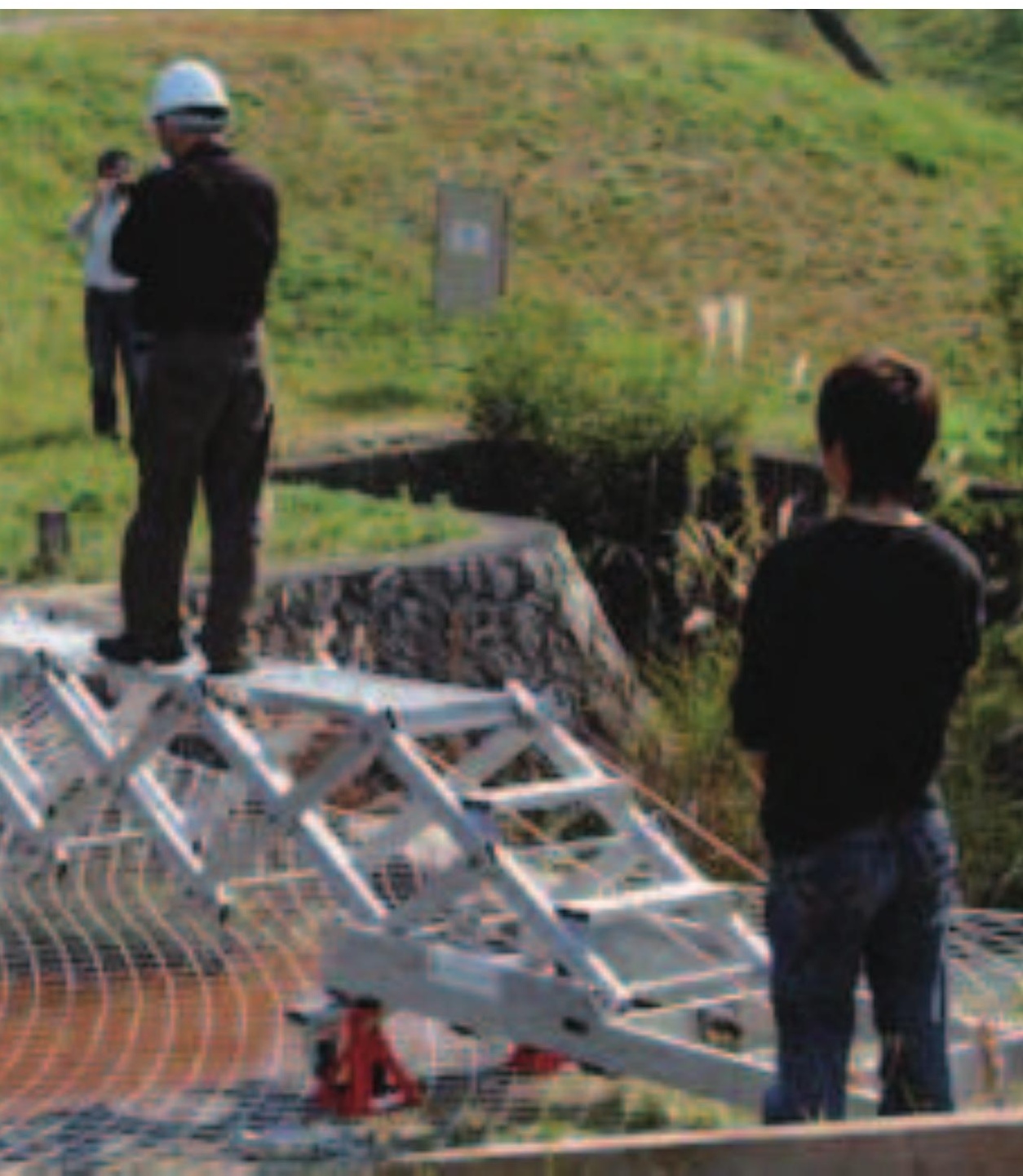


Fig. 7(b)

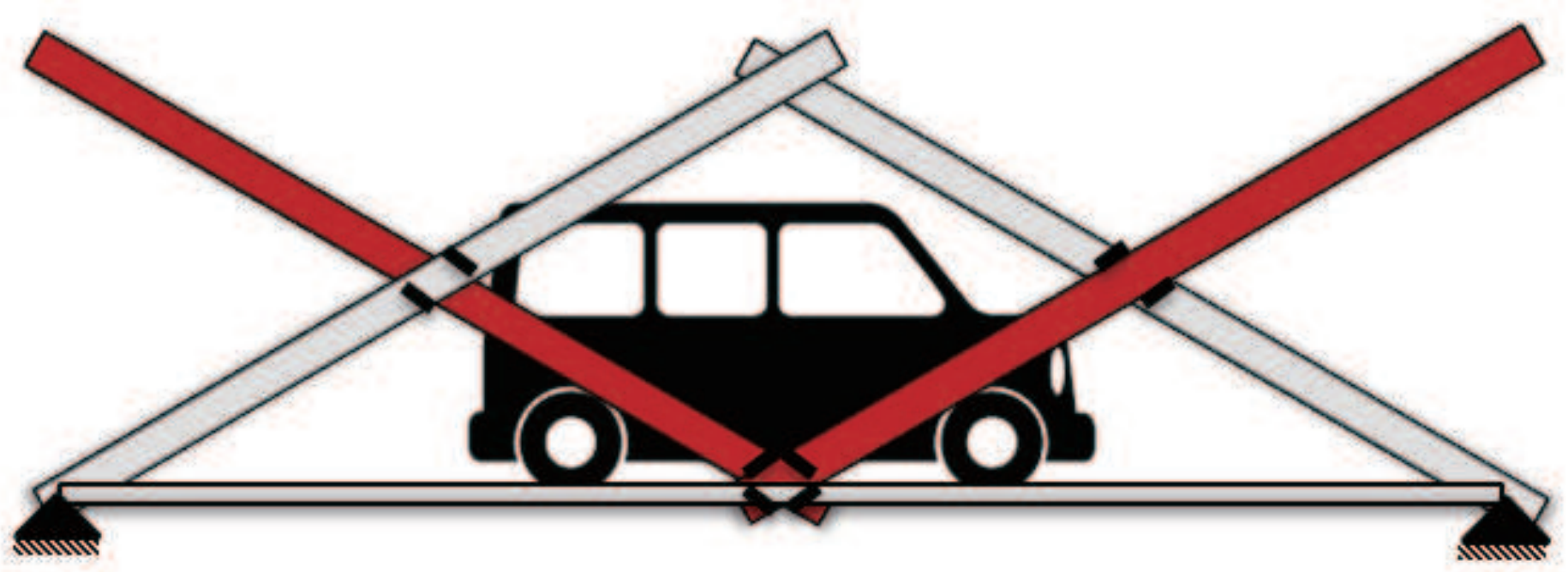

Strain $(\mu \varepsilon)$

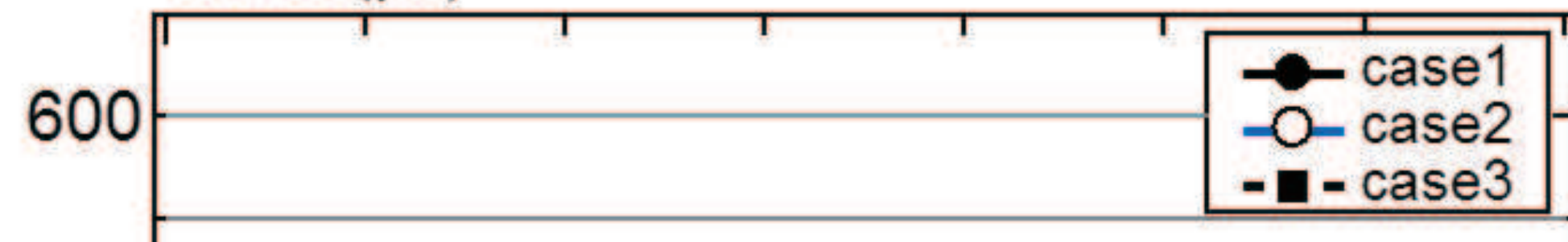

400

200

$-200$

$-400$

$-600$

$0 \quad 1000 \quad 200030004000 \quad 500060007000$ Distance from gate $(\mathrm{mm})$ 
Fig. 9(a)

Strain $(\mu \varepsilon)$
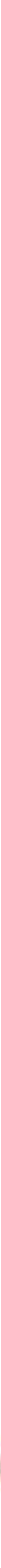

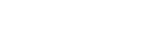

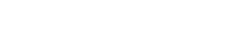

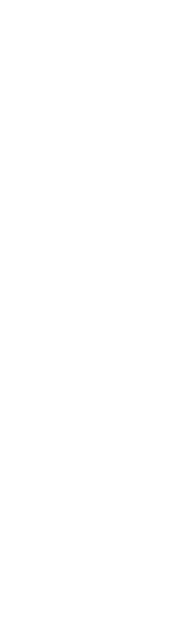


Fig. 9(b)

Strain $(\mu \varepsilon)$
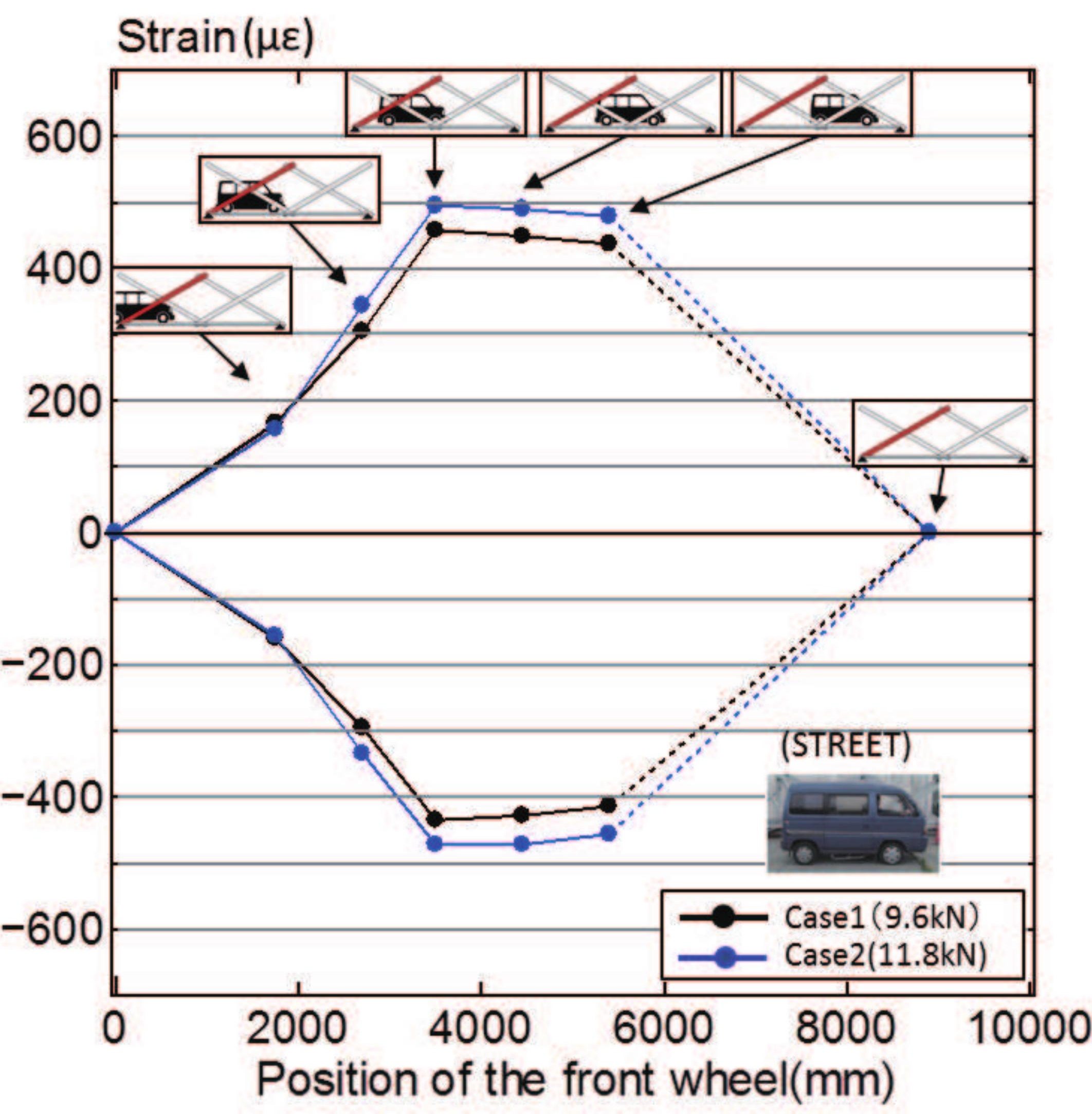
Fig 2(a)

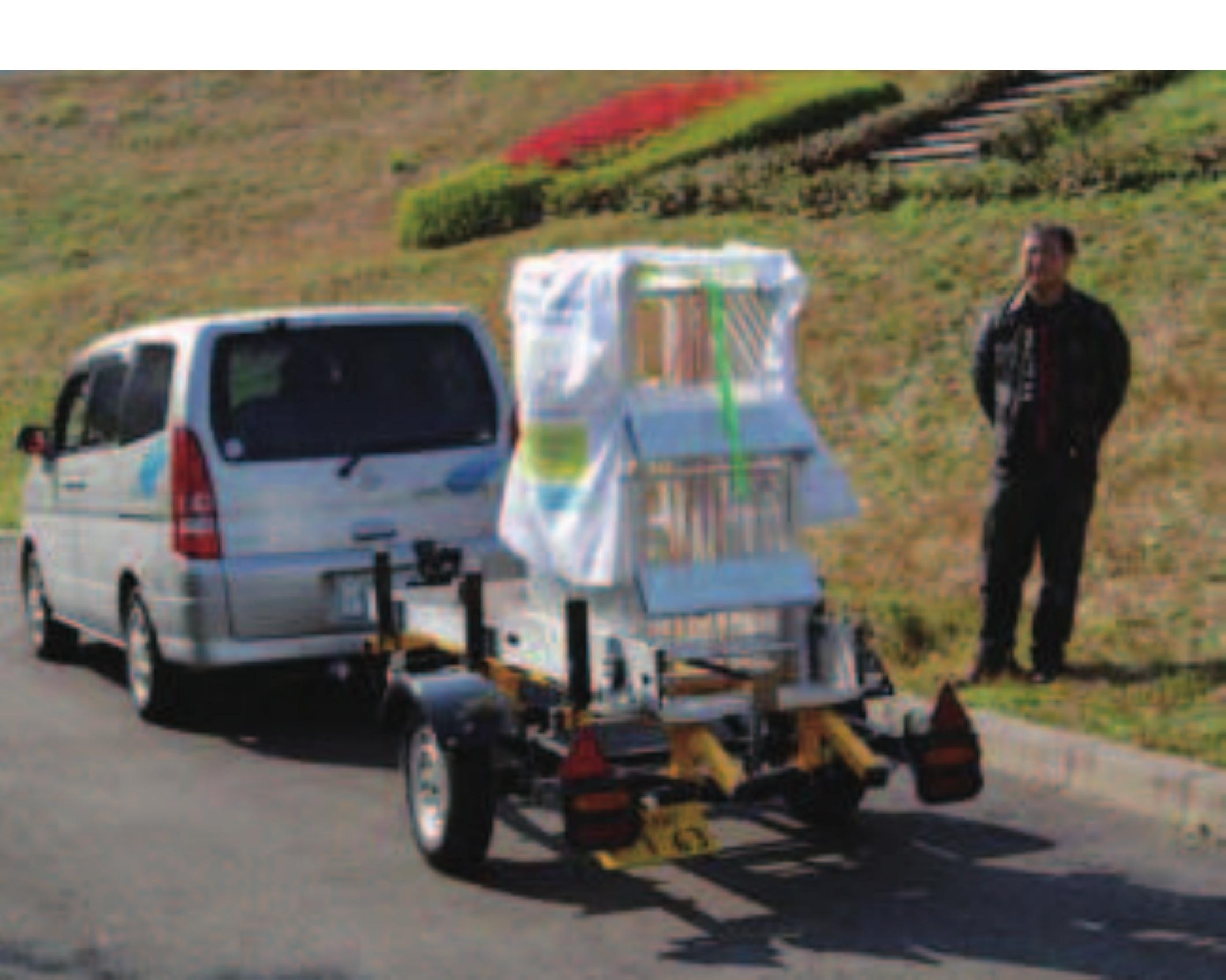

\author{
Fig
}



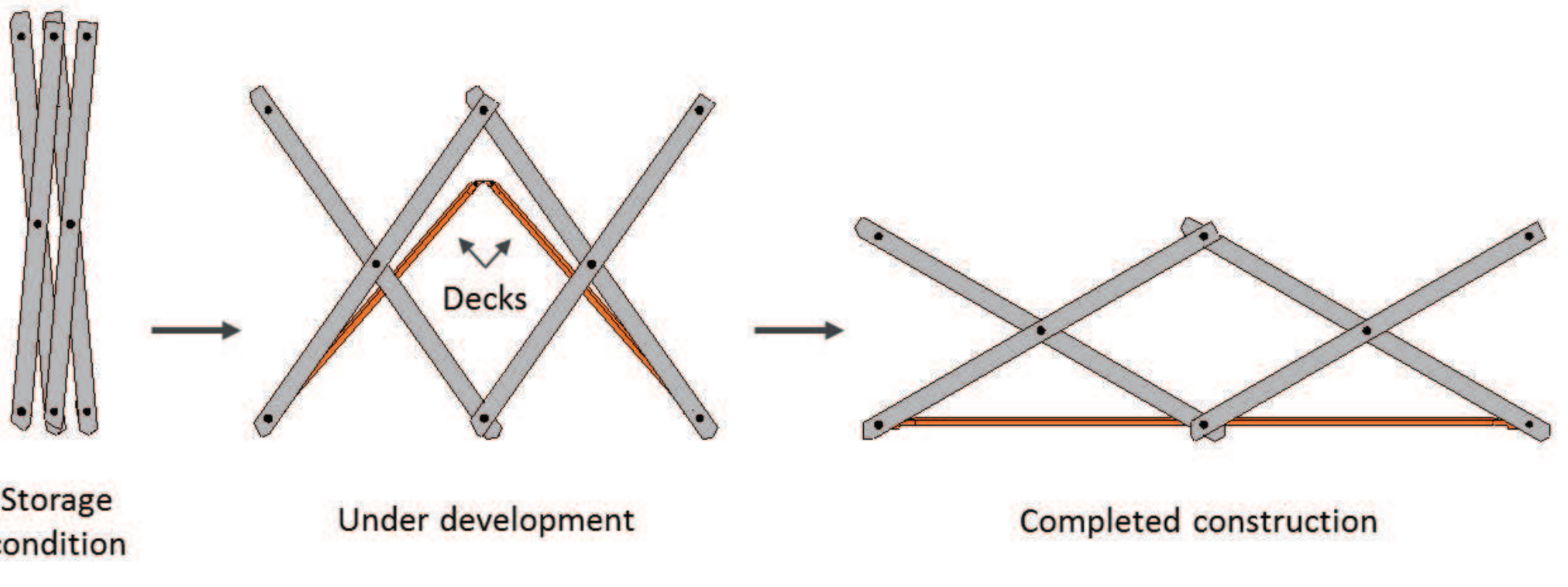

\section{Storage} condition

Fig. 5(a)

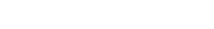



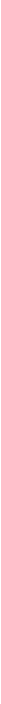

Fig. 5(b) 


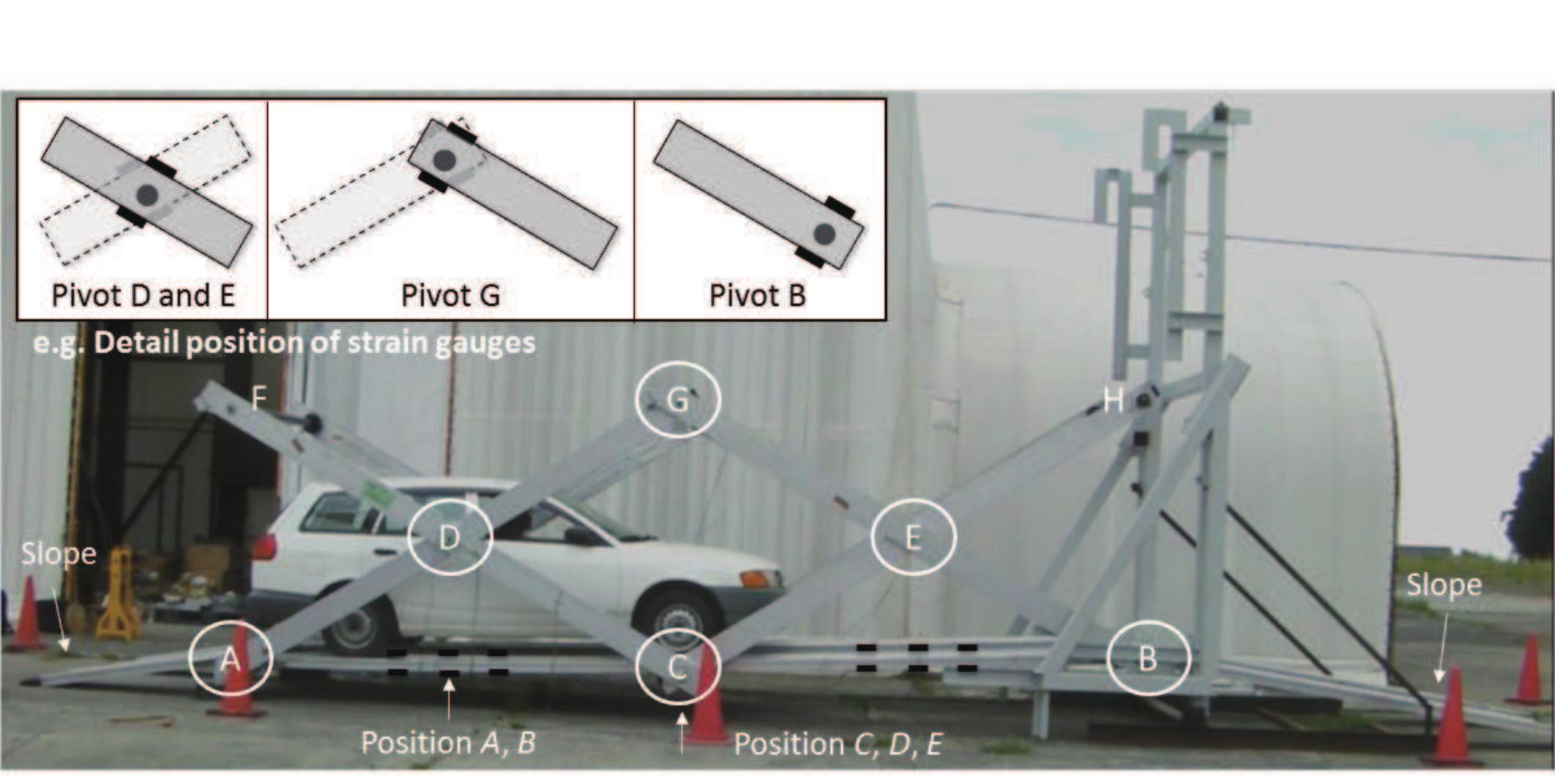

\section{Position $A, B$}

Position $C, D, E$

Fig. 6

.

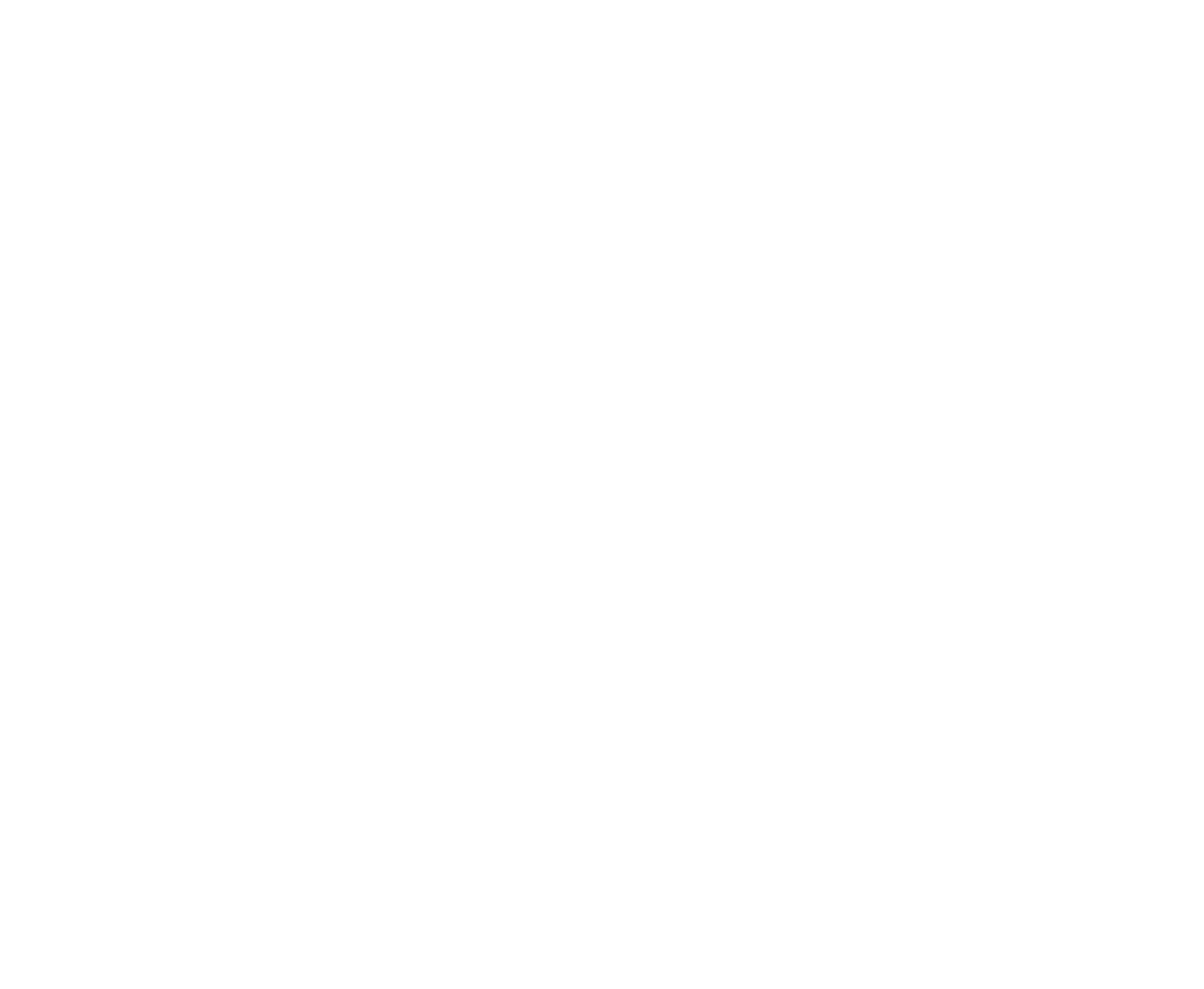




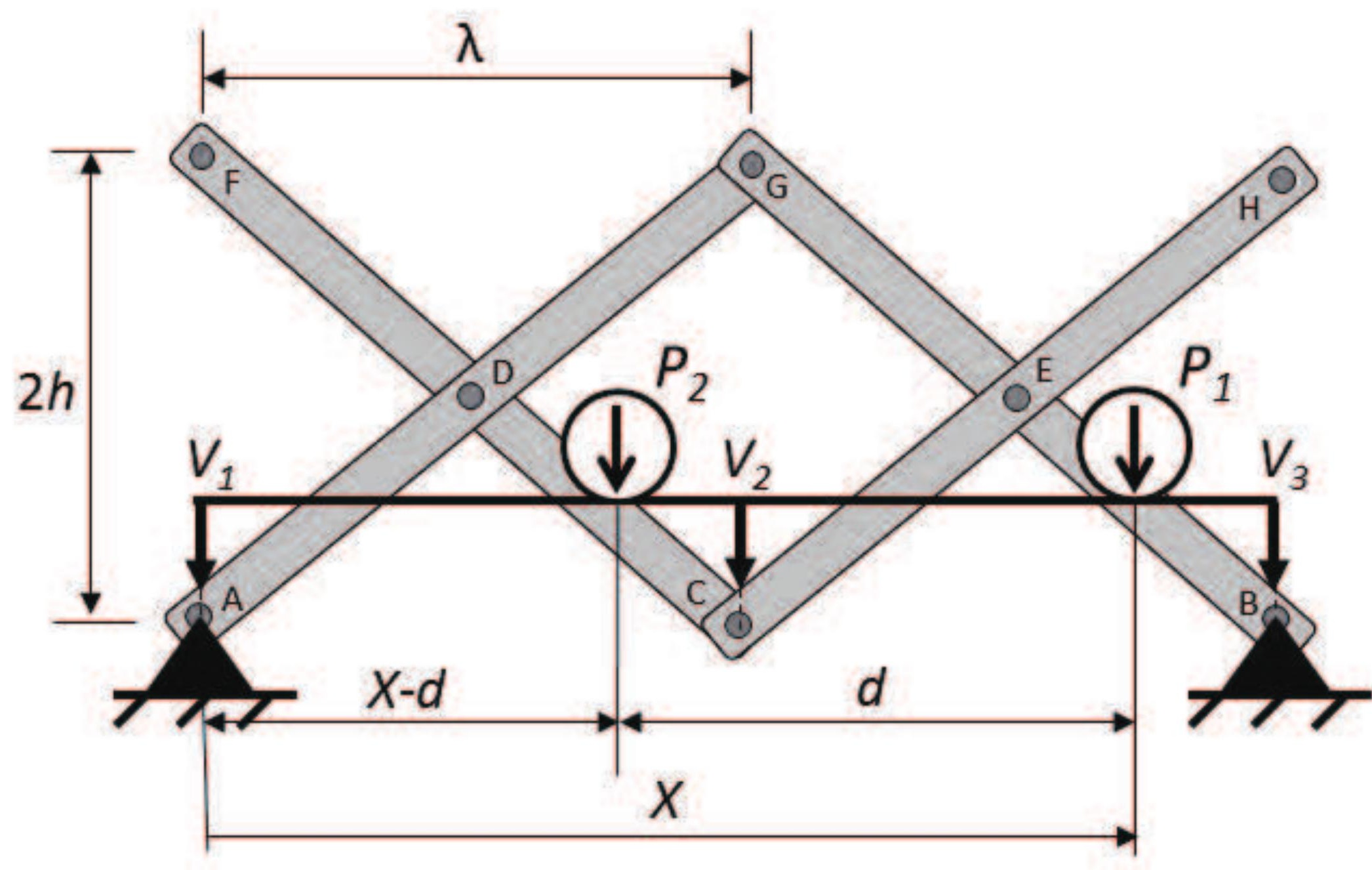

Figure 


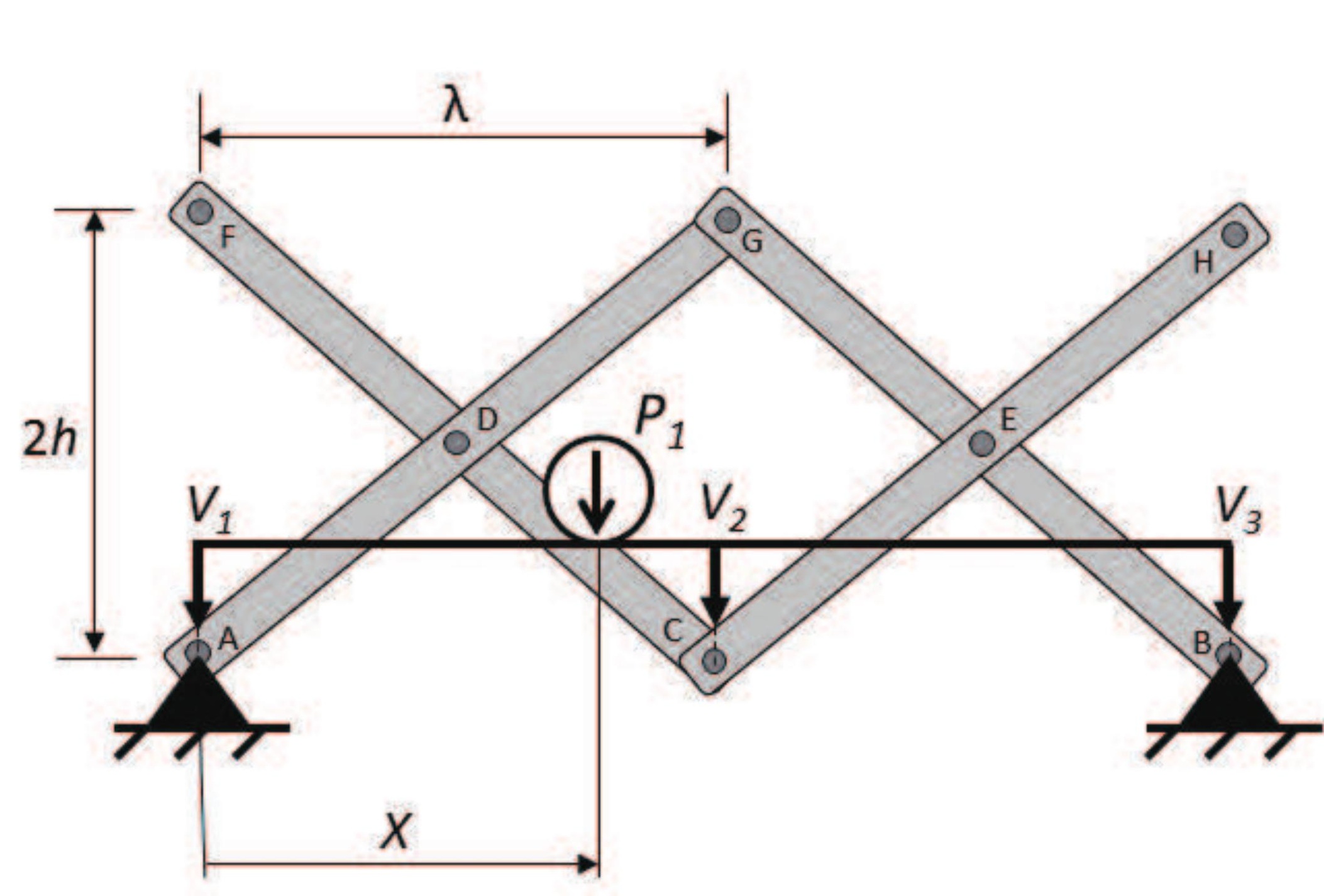

Figure

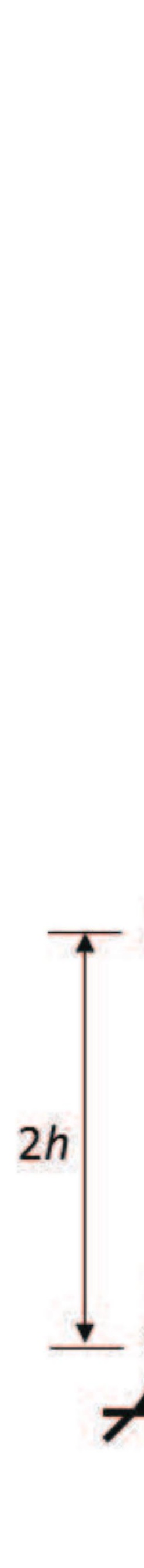

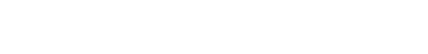

(n)

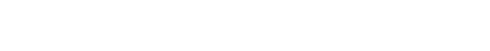

-

-
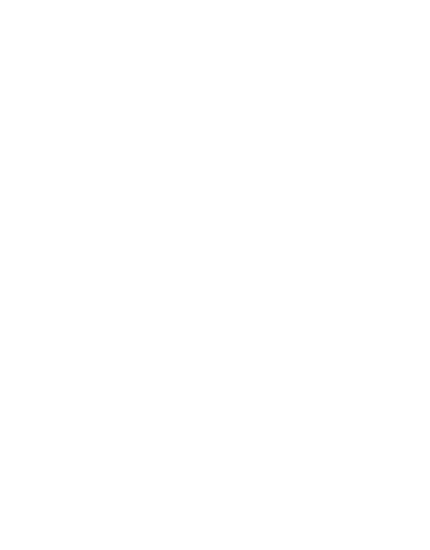


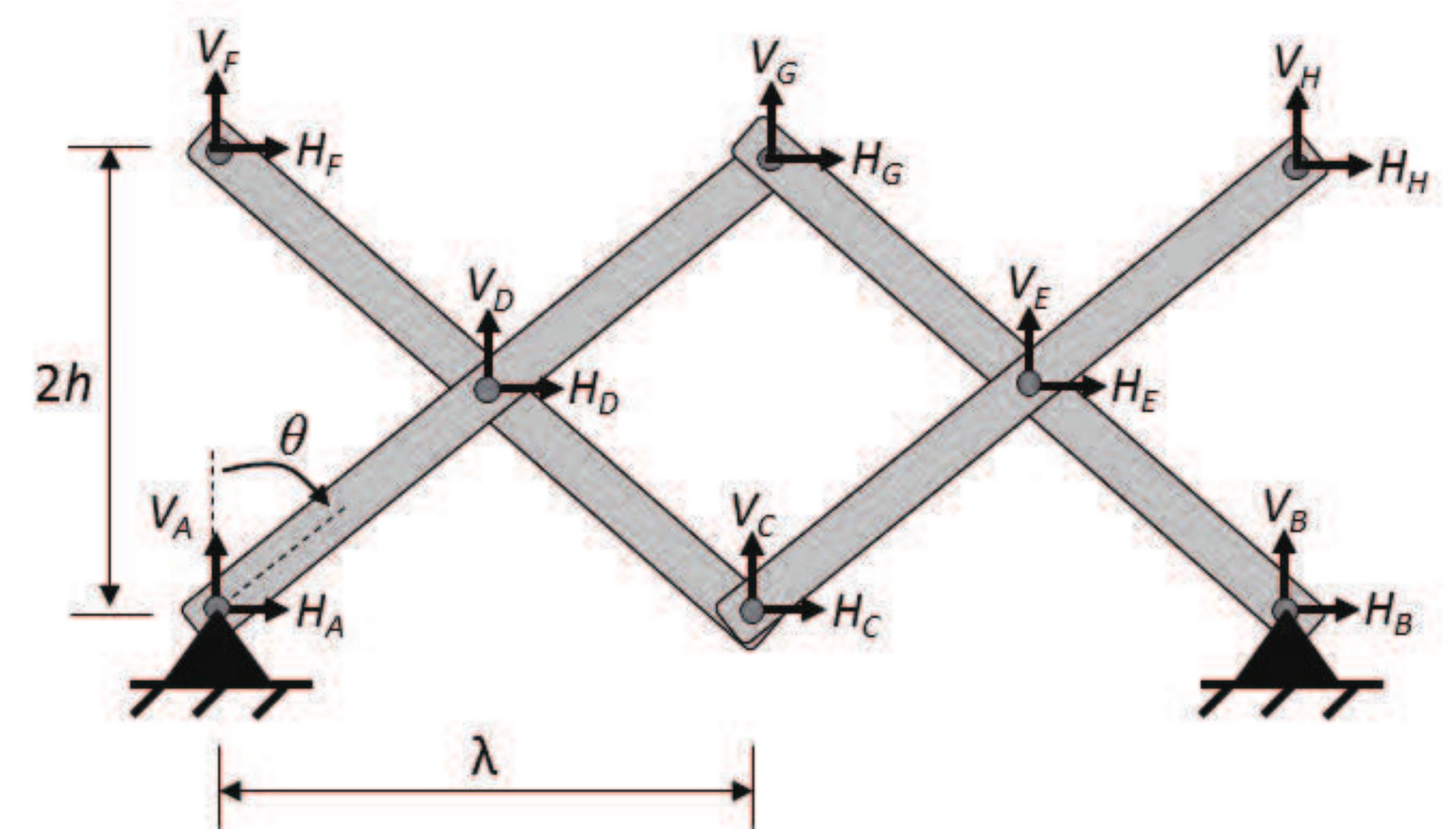


Click here to download LaTeX Source Files: elsarticle.cls 
Click here to download LaTeX Source Files: natbib.sty 